\title{
Recent advances in the application of isoindigo derivatives in materials chemistry
}

\author{
Andrei V. Bogdanov ${ }^{*}$ and Vladimir F. Mironov
}

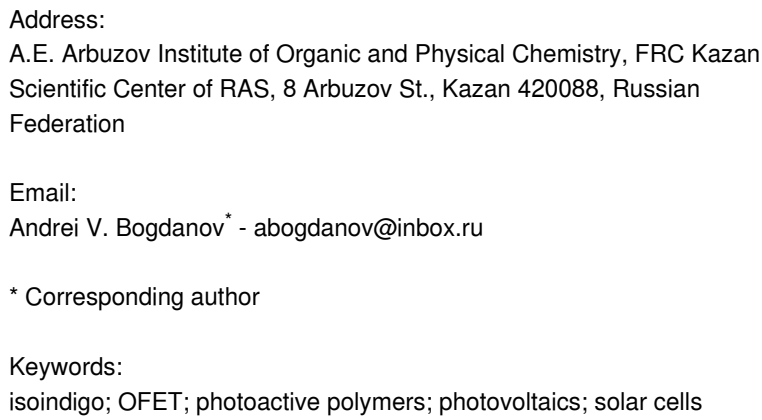

Beilstein J. Org. Chem. 2021, 17, 1533-1564. https://doi.org/10.3762/bjoc.17.111

Received: 07 April 2021

Accepted: 23 June 2021

Published: 06 July 2021

Associate Editor: H. Ritter

(C) 2021 Bogdanov and Mironov; licensee Beilstein-Institut. License and terms: see end of document.

\begin{abstract}
In this review, the data on the application of isoindigo derivatives in the chemistry of functional materials are analyzed and summarized. These bisheterocycles can be used in the creation of organic solar cells, sensors, lithium ion batteries as well as in OFET and OLED technologies. The potentials of the use of polymer structures based on isoindigo as photoactive component in the photoelectrochemical reduction of water, as matrix for MALDI spectrometry and in photothermal cancer therapy are also shown. Data published over the past 5 years, including works published at the beginning of 2021, are given.
\end{abstract}

\section{Introduction}

Among three isomeric bisoxindoles, isoindigo has recently attracted the greatest interest (Scheme 1). The first studies on this class of compounds were related to the field of medicinal chemistry since a number of isoindigo derivatives were found to be highly active against leukemia [1-3]. However, to date, the volume of publications on the study of the biological activity of isoindigo derivatives has been steadily decreasing.

At the same time, the unique properties of the isoindigo structure (planarity, stability, a high degree of conjugation, and electron deficiency) began to attract more and more attention of many research groups. In addition, the ease of modification, such as at the endocyclic nitrogen atom as aromatic fragment of isoindigo, makes it possible to fine-tune the electronic properties. These factors led to the beginning of many studies on isoindigo as a platform for the construction of polymeric materials for various purposes.

\section{Review \\ Organic solar cells (OSCs) on the base of isoindigo derivatives}

Since the pioneering works on the use of isoindigo derivatives in the design of OSCs [3-5], specialists in this field have made significant progress in tuning and improving their properties [6-12]. The main photophysical characteristics that determine 
<smiles>O=C1/C(=C2\Nc3ccccc3C2=O)Nc2ccccc21</smiles>

indigo $\mathrm{C} 2=\mathrm{C} 2$ ' bond<smiles>O=C1Nc2ccccc2/C1=C1/Nc2ccccc2C1=O</smiles>

indirubin $\mathrm{C} 2=\mathrm{C} 3$ ' bond<smiles>O=C1Nc2ccccc2/C1=C1\C(=O)Nc2ccccc21</smiles>

isoindigo $\mathrm{C} 3=\mathrm{C} 3$ ' bond

Scheme 1: Representatives of isomeric bisoxindoles.

the effectiveness of OSCs are open circuit voltage $\left(V_{\mathrm{OC}}\right)$, shortcircuit current $\left(J_{\mathrm{SC}}\right)$ and fill factor $(\mathrm{FF})$. In addition, the solubility of isoindigo derivatives in organic solvents is very important since this affects the morphology of thin films of the photovoltaic cells. To date, the maximum efficiency of $12.05 \%$ has been shown by an OSC based on a composite of a donor poly- thiophene and an acceptor polymeric dicyanoindanone derivative [13]. Among the derivatives of isoindigo, the leading compounds are polymers 1-3, which were used in the design of OSCs as donor components of the active layer. Their power conversion efficiency (PCE) reached more than $8 \%$. The development of an OSC based on low-molecular-weight derivatives of type 4, containing only one isoindigo fragment, also seems promising (Scheme 2).

One of the areas of research is the design of low-molecularweight structures containing one or two isoindigo fragments in a unified conjugated electronic system. Currently, to improve the key characteristics of OSCs, some directions of studies are related to the design of substituents both on the heterocyclic platform (in position 1 and in the aromatic ring) and in the side chain. In the overwhelming majority of works, studies on the photophysical properties of isoindigo derivatives containing a thiophene fragment in position 6 are described. Thus, the authors of References [14,15] obtained a small number of simple representatives of symmetric dithiophene derivatives of isoindigos 5a-c (Scheme 3). The constructed solar cells with an active layer based on a mixture of compounds 5 (donor) and $\mathrm{PC}_{61} \mathrm{BM}$ (acceptor) in a 1:1 ratio showed the dependence of the

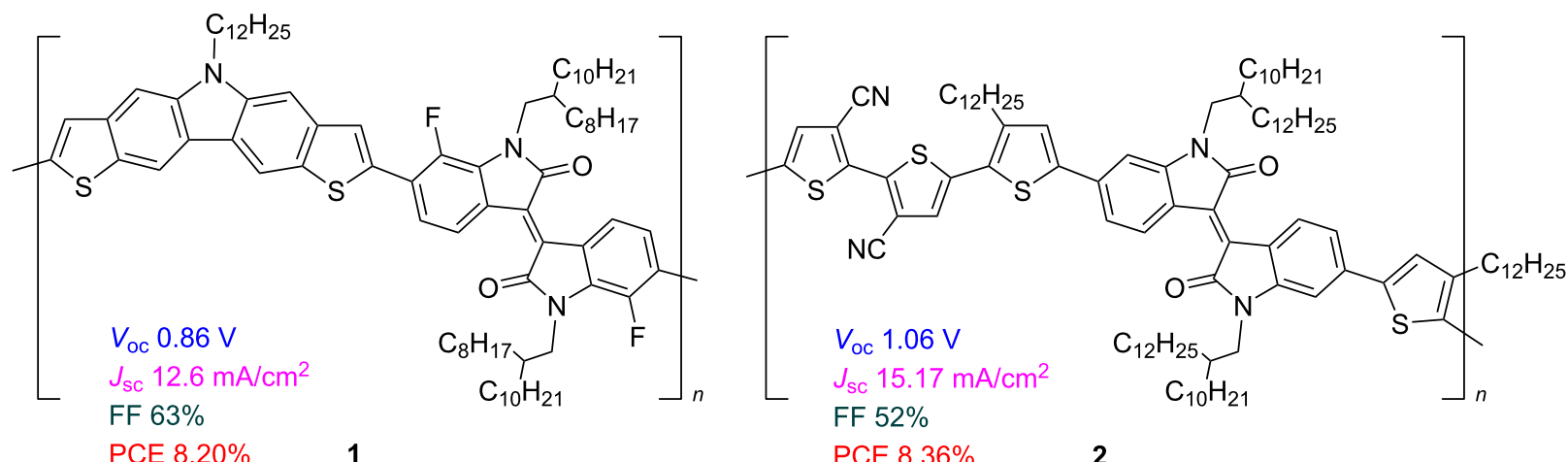

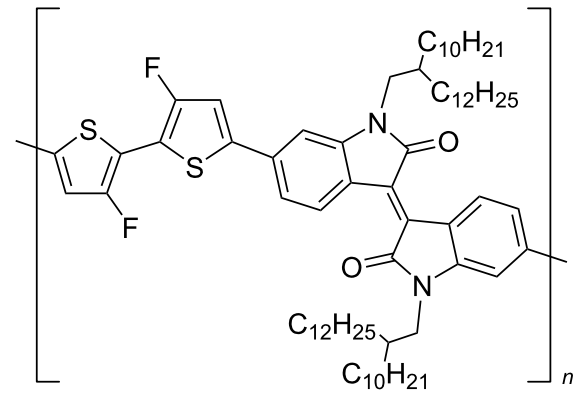

$V_{\text {oc }} 1.06 \mathrm{~V}$

$\mathrm{J}_{\mathrm{sc}} 12.58 \mathrm{~mA} / \mathrm{cm}^{2}$

FF $66 \%$

PCE $8.80 \%$

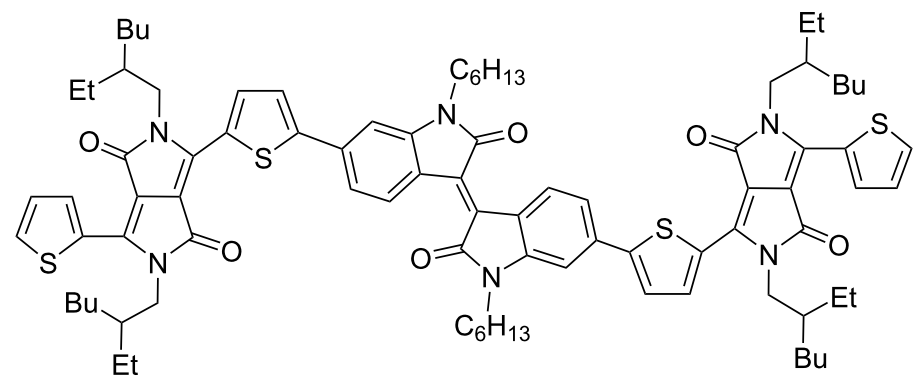

$V_{\text {oc }} 0.86 \mathrm{~V}$

$J_{\mathrm{sc}} 11.75 \mathrm{~mA} / \mathrm{cm}^{2}$

FF $58 \%$

PCE $5.86 \%$ 


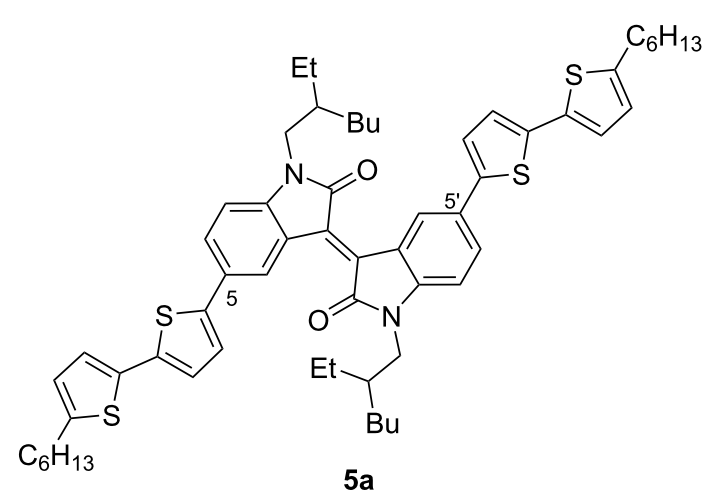

$5 a$

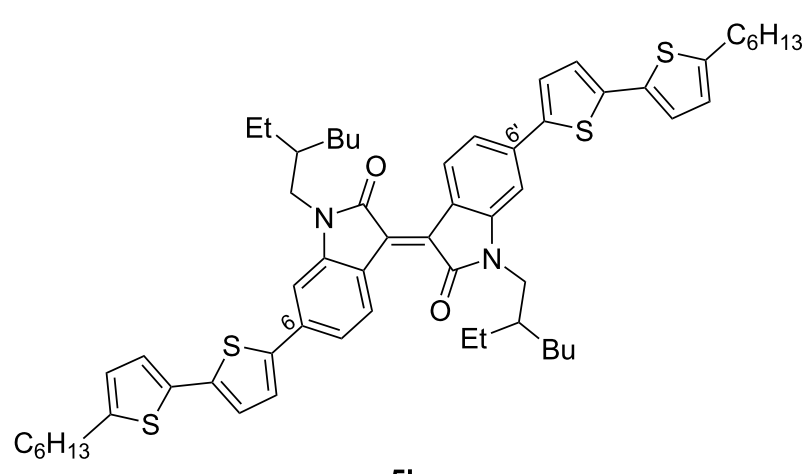

$5 b$

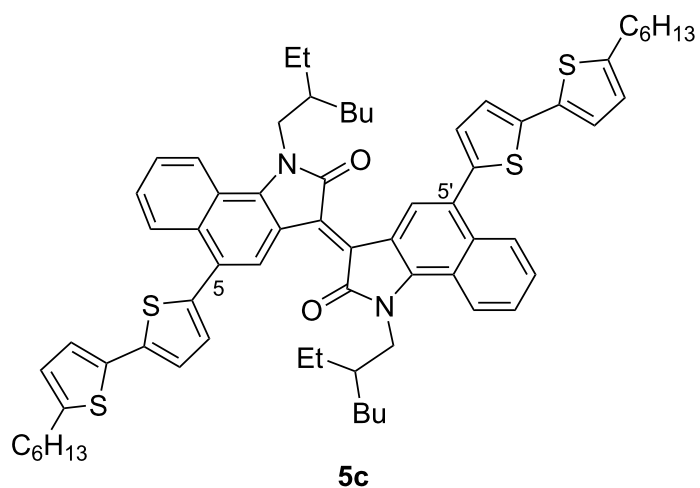

Scheme 3: Monoisoindigos with preferred 6,6'-substitution.

efficiency on the structure and position of substituents in the aromatic fragment of isoindigo. In the presented series, the system based on compound $\mathbf{5 b}$ with an efficiency of $1.25 \%$ turned out to be the best.

It was found [16] that 6,6'-substitution of the isoindigo core is preferable due to the possibility of the formation of a quinoid structure after irradiation with sunlight, which facilitates the transport of electrons through the system (Scheme 4).<smiles>[R]N1C(=O)/C(=C2/C(=O)N([R])c3cc([GaH2])ccc32)c2ccc([GaH2])cc21</smiles><smiles></smiles>

Scheme 4: Possibility of aromatic-quinoid structural transition.

Certain nitrogen heterocycles can be inserted into the substituent chain as an acceptor structural unit (Scheme 5). For exam- ple, an OSC based on a symmetrically substituted isoindigo derivative $\mathbf{4}$ containing a diketopyrrolopyrrole fragment in a mixture with $\mathrm{PC}_{71} \mathrm{BM}$ showed a record efficiency of $5.86 \%$ among oligomeric isoindigo [17]. At the same time, similarly constructed (D-A-D-A) oligomers 6 in the composition with $\mathrm{PC}_{71} \mathrm{BM}$ showed an efficiency of $1.3-1.4 \%$ [18].

Another way to design isoindigoid OSCs is the introduction of aromatic substituents of variable nature into the oligomer structure. By the example of pyrene derivatives $\mathbf{7}$ and $\mathbf{8}$, the dependence of the binding type of the aromatic fragment to the isoindigo core was revealed. The synthetic procedure for the preparation of these monoisoindigoid derivatives is based on the Suzuki reaction. At the same time, pyrene-1-ylboronic acid and 6,6'-dibromoisoindigo were used to introduce a pyrene fragment directly into the isoindigo nucleus, and to obtain a thiophene analogue, pyrenyl-substituted 2-bromothiophene and 6,6'-bis(4,4,5,5-tetramethyl-1,3,2-dioxaborolan-2-yl)isoindigo were used (Scheme 6). Thus, a photovoltaic cell based on thiophene derivative 7 mixed with $\mathrm{PC}_{71} \mathrm{BM}$ showed an efficiency of $1.88 \%$ [19], but if the pyrenyl substituent is bonded directly to the isoindigo core, the efficiency of such an OSC turns out to be significantly lower $(0.10 \%)$ [20]. 


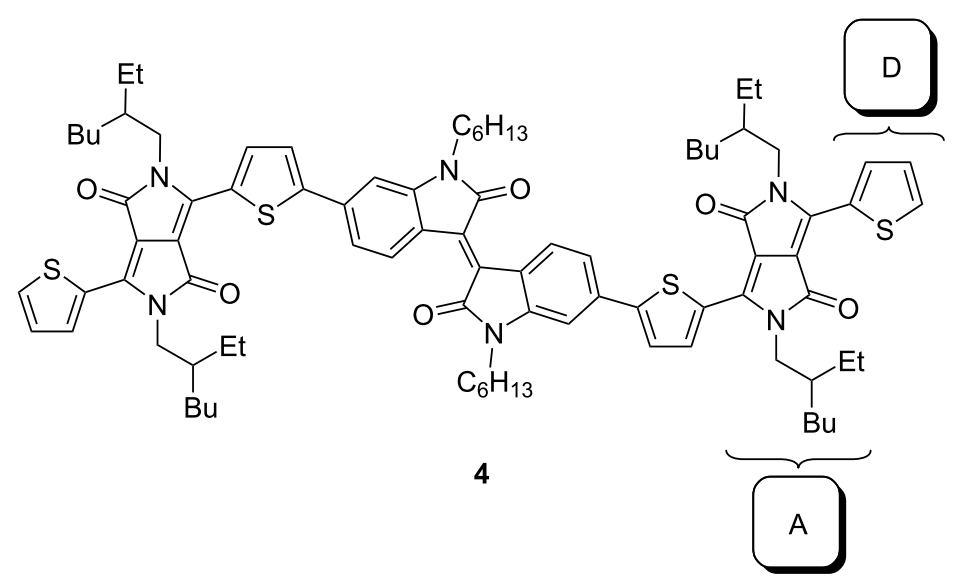<smiles>[R]c1ccc(-c2ccc(-c3ccc(-c4sc(-c5ccc6c(c5)OCCO6)c5c4OCCO5)c4nsnc34)s2)s1</smiles>

Scheme 5: Isoindigo structures with incorporated acceptor nitrogen heterocycles.

One of the highest efficiency values (4.7\%) among low-molecular-weight isoindigo derivatives was shown by a two-component OSC based on isoindigo 9a, containing an alkoxylated p-phenylene fragment and $\mathrm{PC}_{71} \mathrm{BM}$ in a ratio of 1:0.7 (w/w), a thin film of which was obtained from chloroform with 0.5 vol $\% N$-methylpyrrolidone (Scheme 7). As the authors believe [21], the addition of this viscous solvent made it possible to provide a better surface morphology of a thin-film layer since without it, the efficiency was almost two times lower $(2.8 \%)$. Therein, the key role of the structure of the acceptor terminal substituent was also revealed since a similar OSC based on the rhodamine derivative $\mathbf{9 b}$ showed an efficiency of only $0.66 \%$ (Table 1 ).

It is important to note that the replacement of the thienylphenylene spacer in structure 9a by the acceptor indan-3-dicyanoethylidene-1-one-2-ylidene fragment in compound $\mathbf{9 c}$ led to a decrease in the efficiency to $2.82 \%$ [22].

Perylene diimide-derived isoindigo derivative $\mathbf{1 0}$ was used as an acceptor in the creation of a nonfullerene OSC with thiophene polymer 11 as a donor component (Scheme 8). The PCE value of such a device turned out to be $2.6 \%$.

Cho et al. constructed a three-component cell in which the active layer consisted of a donor $\mathbf{1 1}$ and a polymeric acceptor based on perylene diimide 12 [23]. One of the simplest thiophene derivatives of isoindigo $\mathbf{1 3}$ was used here only as an additive (10 wt \%), leading to an increase in efficiency from $5.9 \%$ to $6.8 \%$ (Scheme 9). Using a variety of physical methods, it has been proven that the presence of isoindigo 13 in the three-component mixture provides tighter packing of the thin layer and larger crystalline domains. This, in turn, leads to an increase in the decay time of the exciton and, as a consequence, to a high $J_{\text {SC }}$ value.

Several works have been devoted to the use of compounds containing two isoindigo units in the molecule for OSC creation. Scheme 10 shows examples of structures in which isoindigo fragments are linked either through a thiophene spacer $\mathbf{1 4}$ or through an embedded phenylene substituent $\mathbf{1 5}$. 


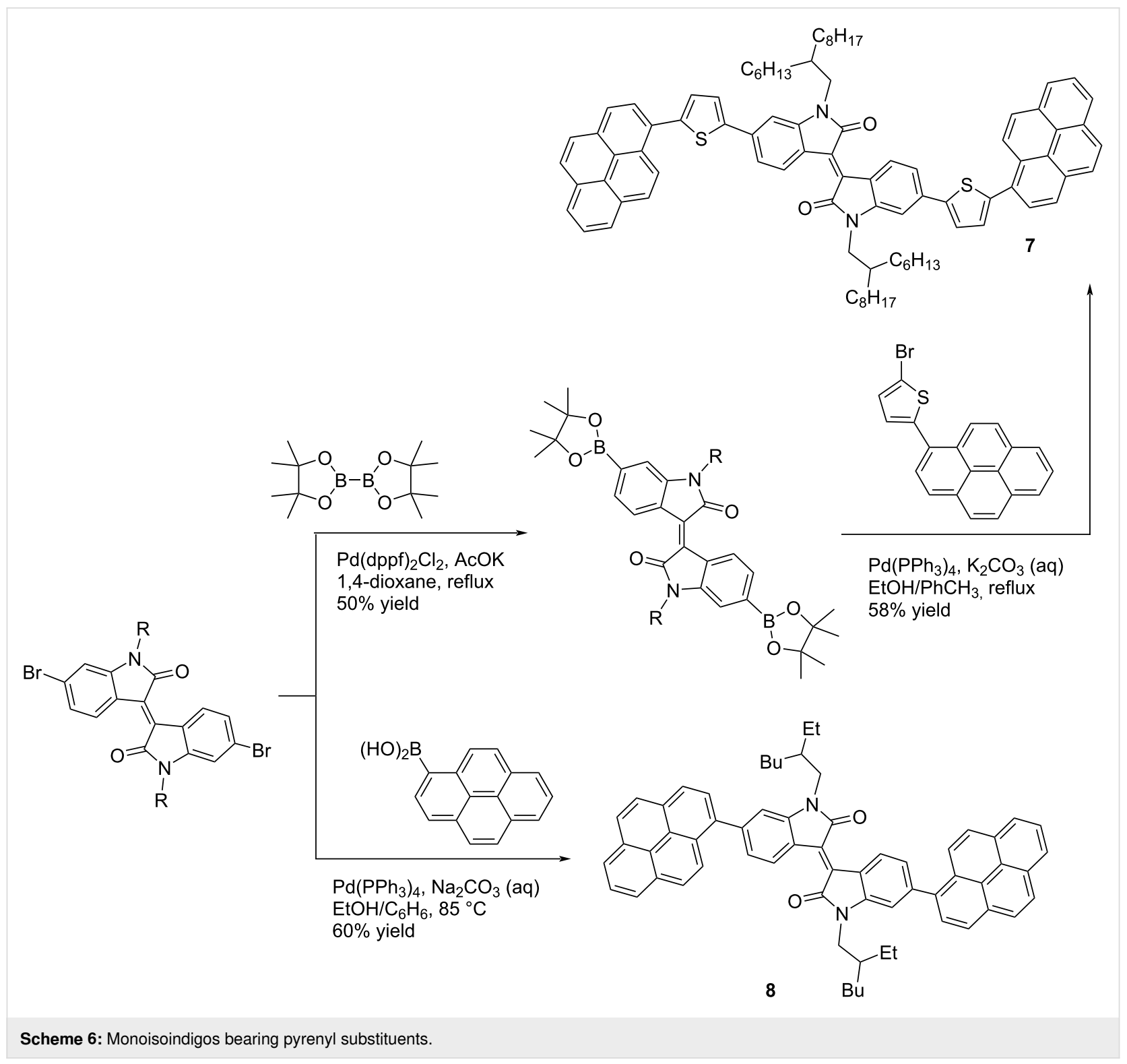

Thus, in the series of thiophene-centered bisisoindigos 14a-d, the best efficiency values were shown by OSCs containing an odd number of thiophene units (14a: $2.16 \%$; 14c: $2.40 \%)$ [24]. A cell based on compound $\mathbf{1 5 b}$ showed a close value of efficiency $(2.25 \%)$ [25]. At the same time, incorporation of the tetrafluorophenylene fragment into the center of the molecule 14a and the presence of a branched alkyl substituent at the nitrogen atom made it possible to improve the characteristics of the cell [26]. After annealing such an $\mathrm{OSC}$ at $80{ }^{\circ} \mathrm{C}$, the efficiency was increased from 3 to $3.18 \%$. It should be noted that in all cases mentioned here, $\mathrm{PC}_{71} \mathrm{BM}$ was used as the acceptor component of the OSC active layer. The photovoltaic characteristics of the OSCs based on compounds of this type are summarized in Table 2.
It has been shown that oligomeric isoindigos that do not contain a thiophene fragment can also be used as donor components of the OSC. The synthesis of such compounds is also based on the Suzuki coupling reaction between alkylated 6,6'-dibromoisoindigos and corresponding arylboronic derivatives, leading to the formation of target molecules in moderate yield (Scheme 11). In these compounds, the triarylamine substituent is linked either directly to the isoindigo core or via a vinylphenylene bridge (see compounds $\mathbf{1 7 a}, \mathbf{b}$ ) [27,28]. The presence of the latter determines the cell efficiency to be an order of magnitude higher (3.57\%) then when using 16a and $16 b$.

In the chemistry of isoindigo-based materials, the most popular and most studied direction in the creation of OSCs is the use of 


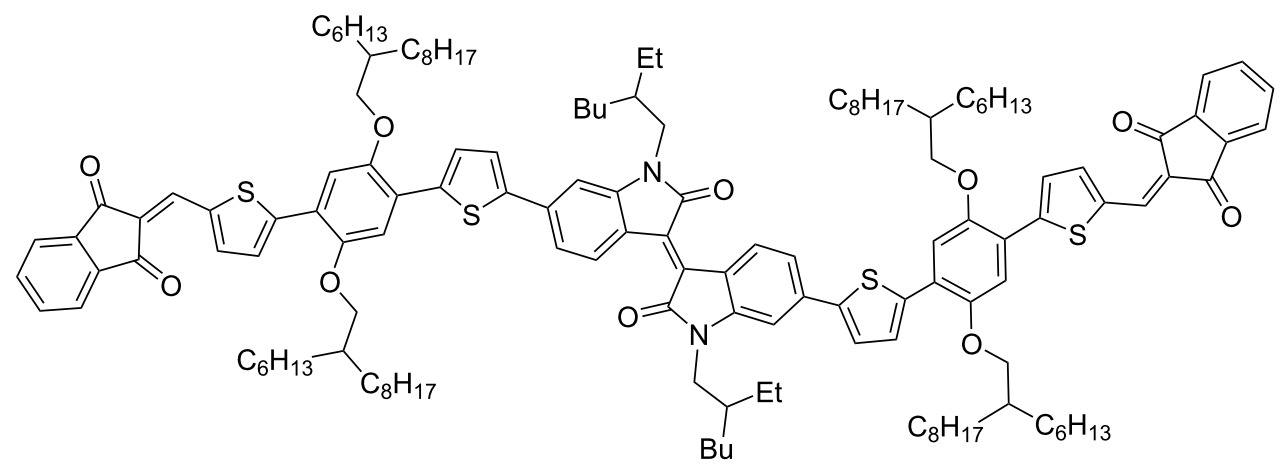

9a

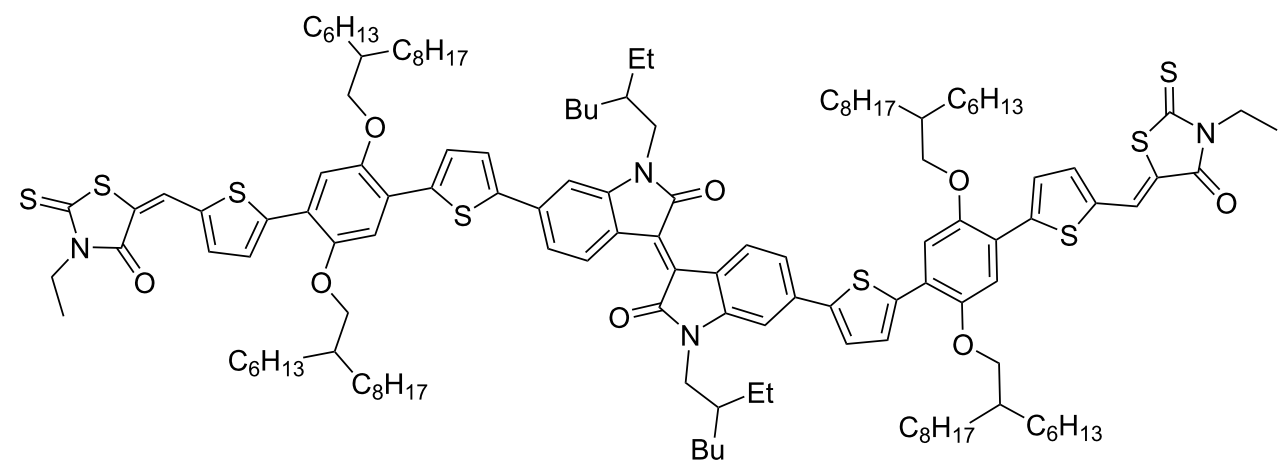

$9 b$

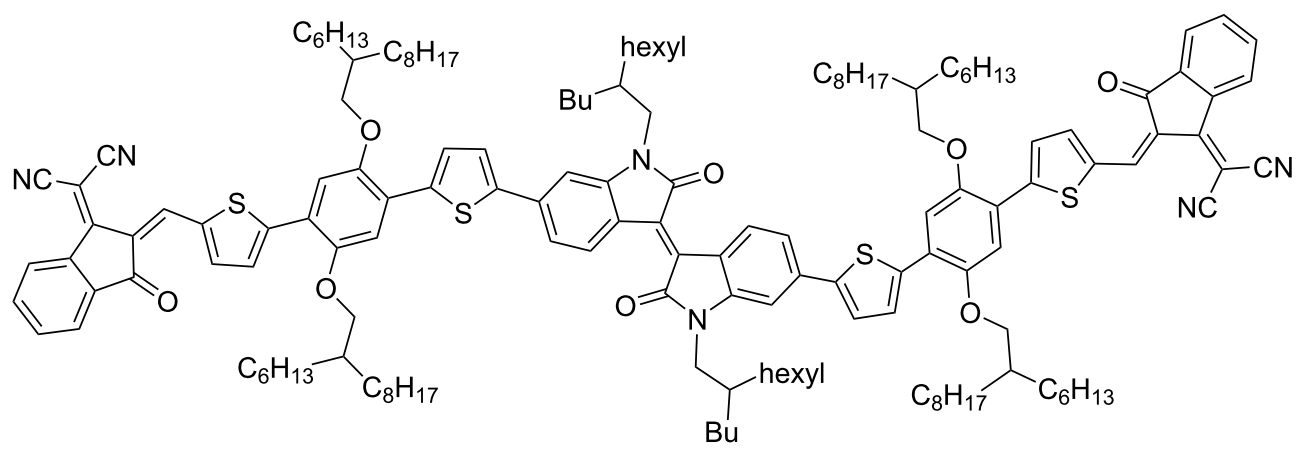

9c

Scheme 7: $p$-Alkoxyphenylene-embedded thienylisoindigo with different acceptor anchor units.

\begin{tabular}{|c|c|c|c|}
\hline compound & second component (w/w) & additive & PCE, \% \\
\hline $9 a$ & $\mathrm{PC}_{71} \mathrm{BM}(1: 0.5)$ & none & 2.13 \\
\hline $9 a$ & $\mathrm{PC}_{71} \mathrm{BM}(1: 0.7)$ & none & 2.85 \\
\hline $9 a$ & $\mathrm{PC}_{71} \mathrm{BM}(1: 0.7)$ & NMPa & 4.70 \\
\hline $9 b$ & $\mathrm{PC}_{71} \mathrm{BM}(1: 0.7)$ & none & 0.66 \\
\hline $9 b$ & $\mathrm{PC}_{71} \mathrm{BM}(1: 0.7)$ & NMP & $-\mathrm{b}$ \\
\hline $9 c$ & $\mathrm{~J} 61(1.3: 1)$ & $\mathrm{DPE}^{\mathrm{C}}$ & 2.82 \\
\hline
\end{tabular}

a $N$-Methylpyrrolidone. ${ }^{b}$ Not possible to measure. ${ }^{\mathrm{c}}$ Diphenyl ether. 


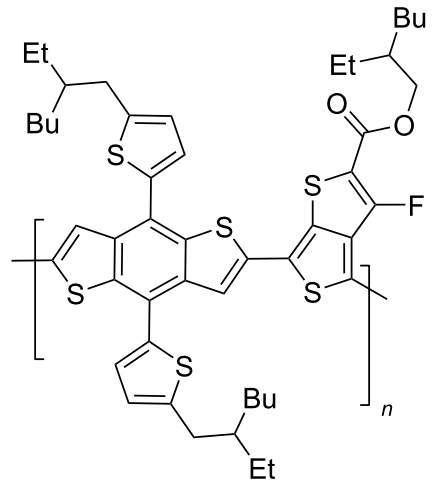

11

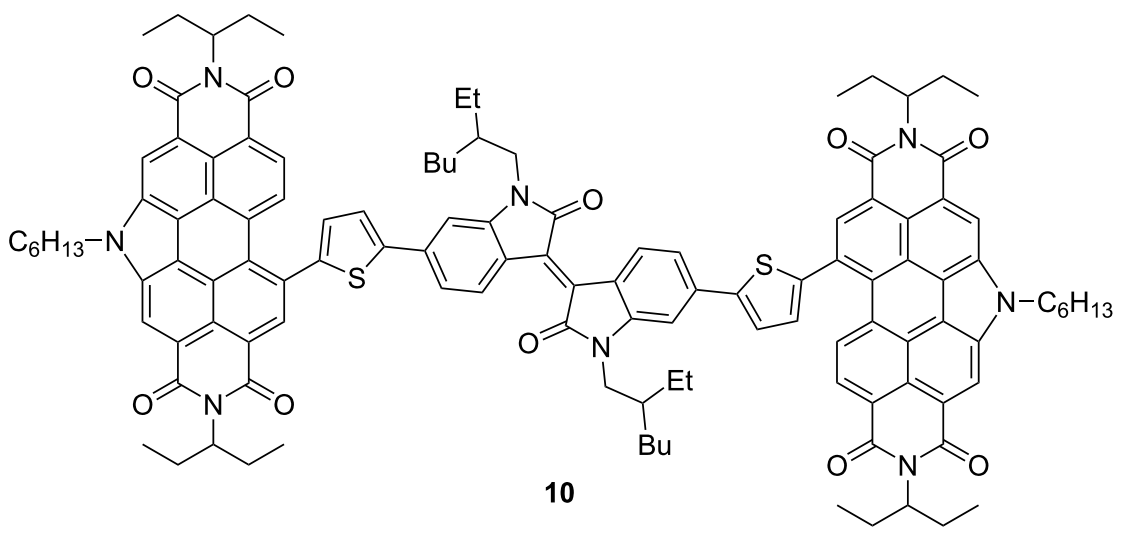

Scheme 8: Nonfullerene OSC based on perylene diimide-derived isoindigo.

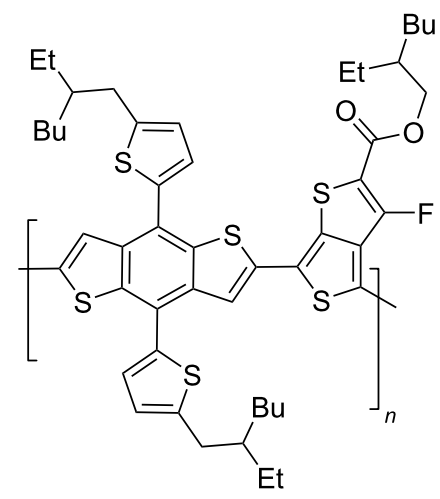

11

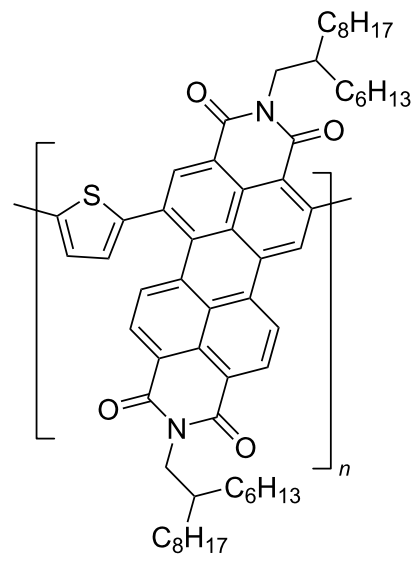

12

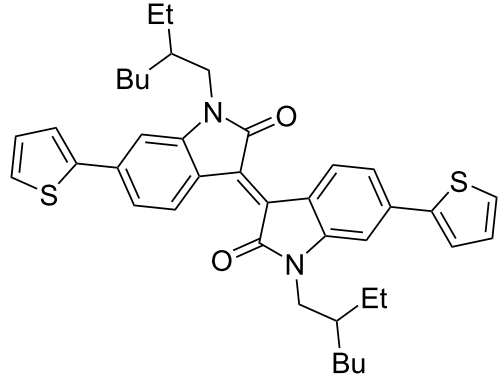

13

Scheme 9: Isoindigo as an additive in all-polymer OSCs.

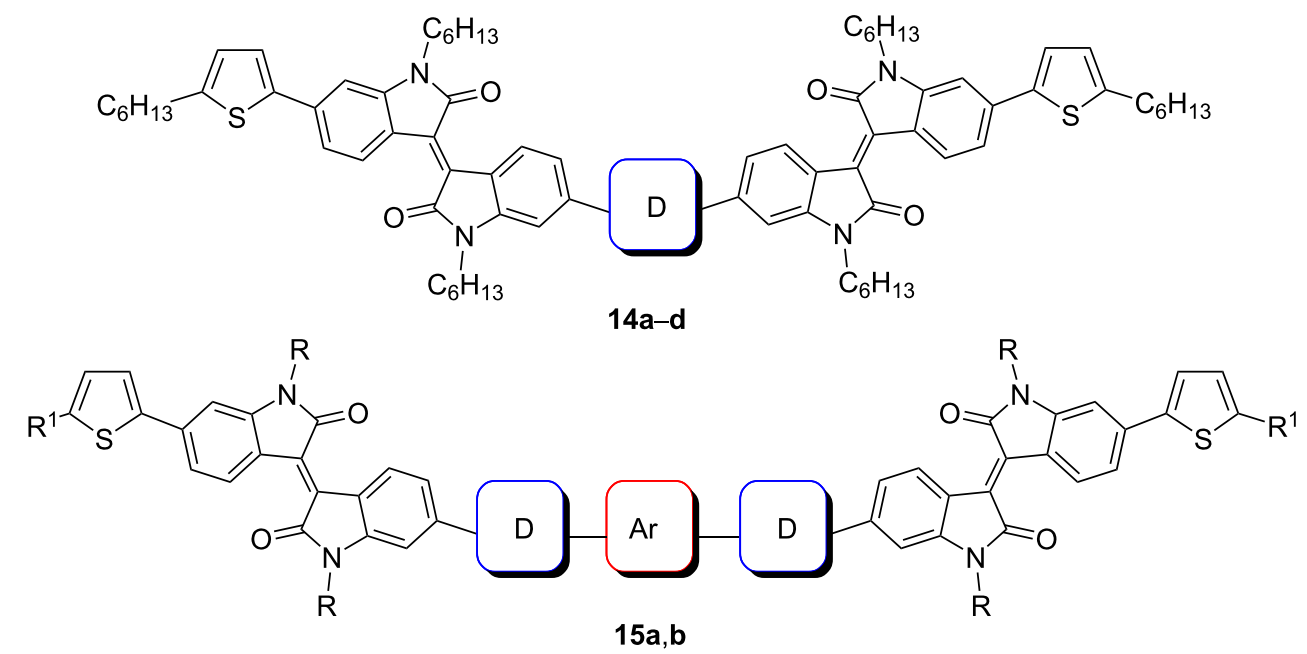

Scheme 10: Bisisoindigos with different linker structures. 


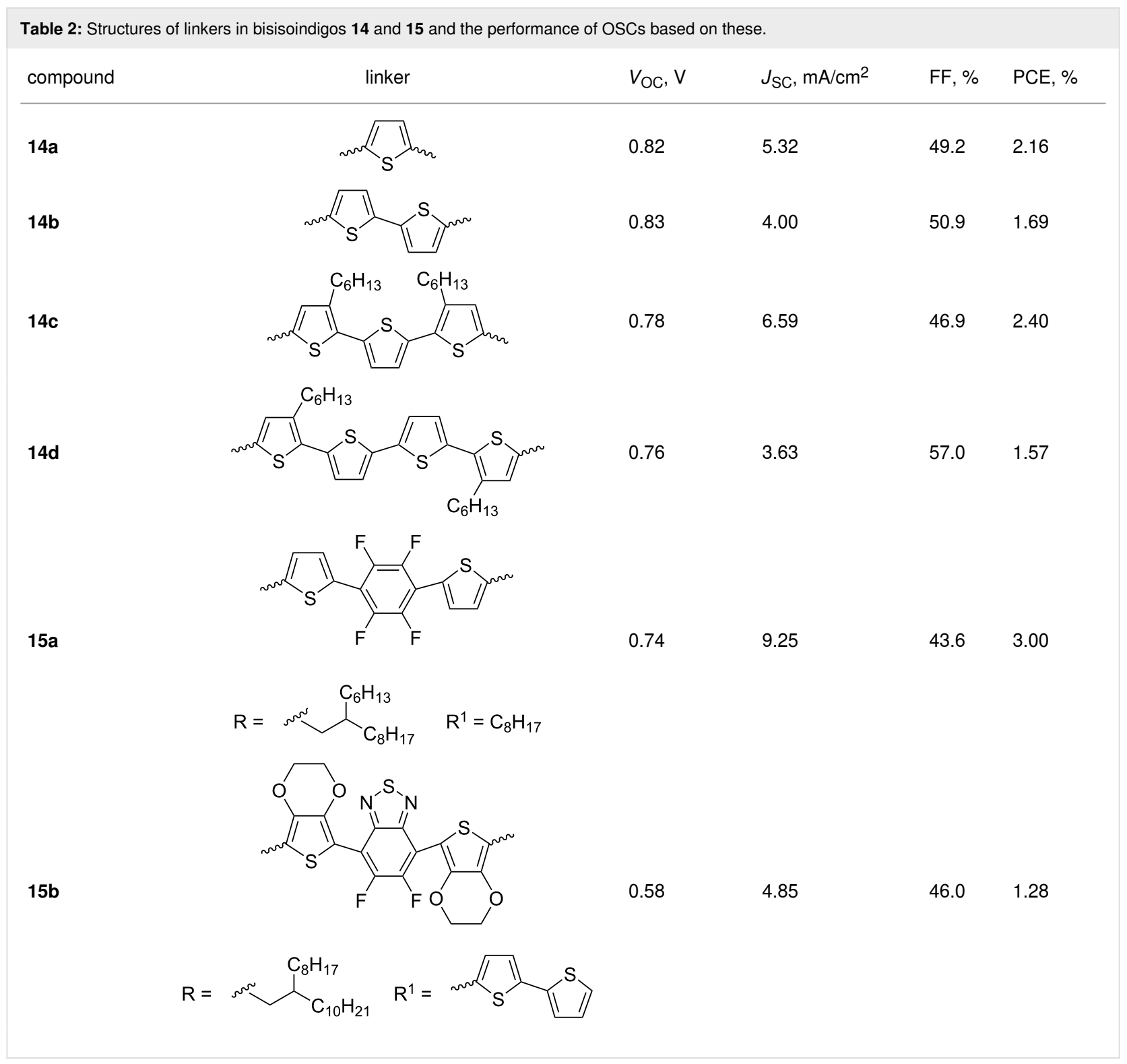

polymer structures containing an isoindigo fragment in a monomer unit associated with a different number of thiophene substituents (Scheme 12).

By the example of one of the simplest representatives of this type of polymers, a significant effect of the structure of the substituent at the nitrogen atom of the heterocycle on the OSC efficiency was also shown $[29,30]$. Thus, fluorine-substituted polymers 18a,b in the composition with $\mathrm{PC}_{61} \mathrm{BM}$ showed a PCE of only $0.9-1.4 \%$, while an OSC based on ethoxylated derivative 19a was characterized by a high short-circuit current $\left(J_{\mathrm{SC}}=\right.$ $13.92 \mathrm{~mA} / \mathrm{cm}^{2}$ ), with a 5 -fold better PCE value (Table 3).

Expansion of the conjugation chain by introducing additional electron-enriched condensed heterocyclic fragments (see com- pounds 20 and 21) makes it possible to achieve a PCE of almost 6\% (Scheme 13) [31-33].

In the course of further studies, the key influence of the nature of both the substituent at the nitrogen atom of isoindigo and at the bithiophene moiety on the OSC efficiency was confirmed. Thus, the introduction of fluorine atoms to thiophene rings in compound 22b leads to an increase in the efficiency from 4.58 to $6.21 \%$. Based on the data of quantum chemical calculations, Park et al. [34] showed that in the fluorinated derivative, the dihedral angle between the thiophene rings is $0.88^{\circ}$ (for comparison, in compound 22a it is $17.55^{\circ}$ ), which provides better planarity of the polymer and, as a consequence, higher velocity transport of electrons under irradiation. Within the framework of this direction, the importance of the method for preparing a 


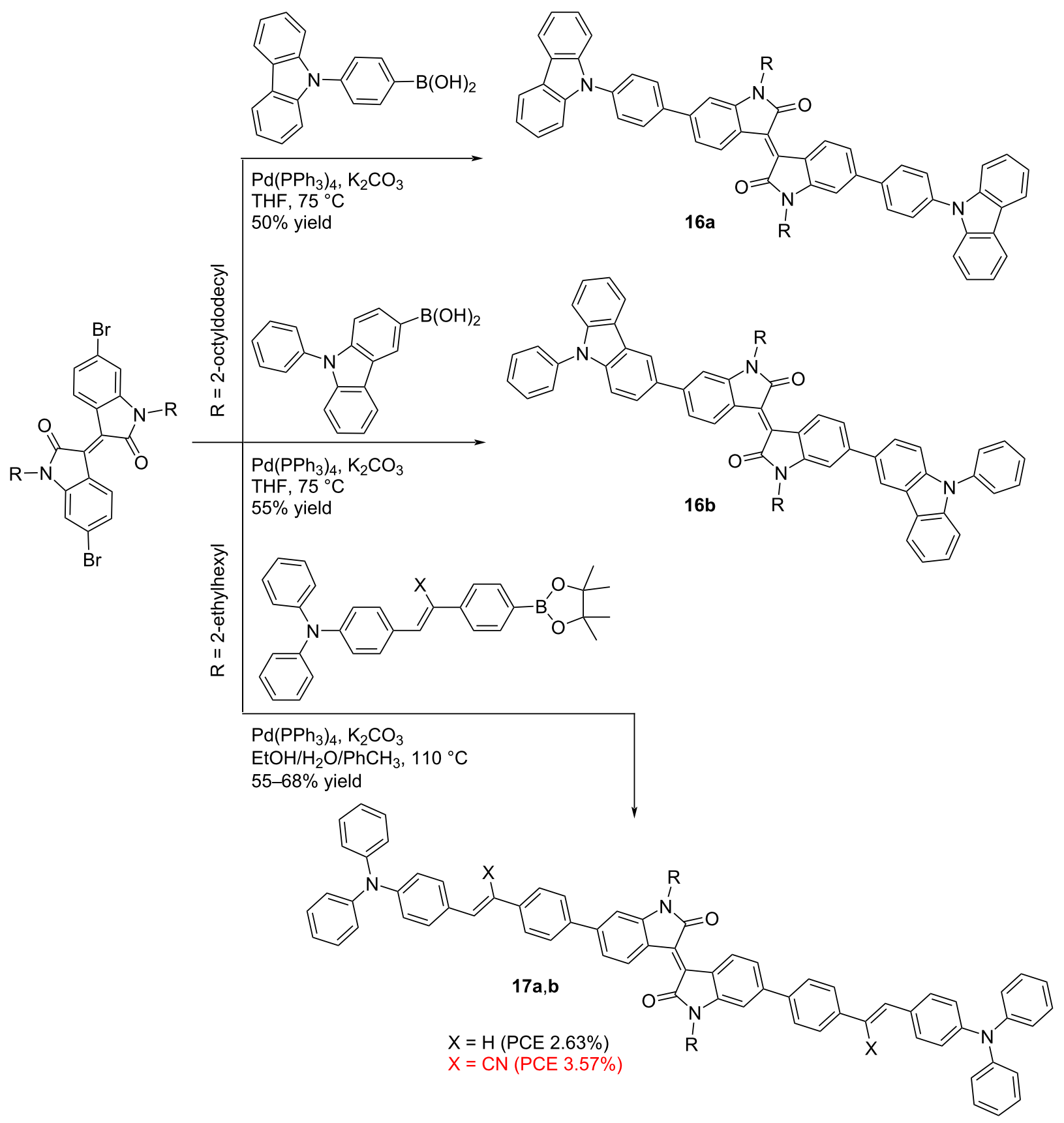

Scheme 11: Nonthiophene oligomeric monoisoindigos for OSCs.

thin film of the active layer of OSC was also shown. In reference [35], the OSCs based on a mixture of polymers $\mathbf{2 3 a}, \mathbf{b}$ with $\mathrm{PC}_{71} \mathrm{BM}$ and an additive of diphenyl ether ( 3 vol \%) were obtained by spin coating from an $o$-xylene solution. Therein, the fluorinated analog also turned out to be better in terms of the final value of the efficiency. Dithienosylole polymers 24 can also be included in this structure type. Although the authors of reference [36] do not give the exact values of the molecular weight of the obtained polymers, they draw a conclusion about the influence of the molecular weight on the efficiency of the cells (Table 4).

Thus, when using polymer $\mathbf{2 4 b}$ obtained by the Suzuki reaction with bis(pinacolato)diboron, the OSC efficiency was only $0.99 \%$, while the Stille method gave a polymer 24a characterized by an efficiency of $1.66 \%$ (Scheme 14 ). 


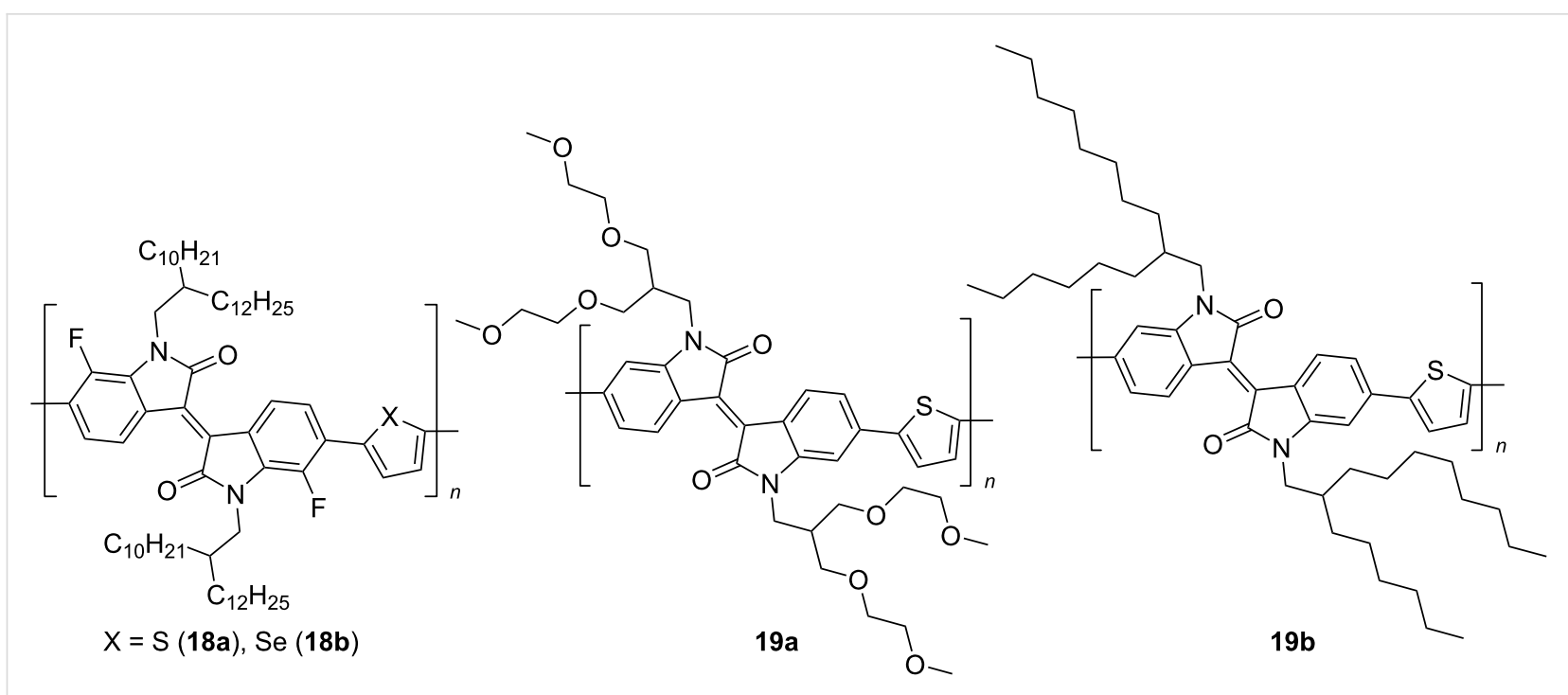

Scheme 12: The simplest examples of polymers with a monothienylisoindigo monomeric unit.

Table 3: Photovoltaic properties of OSCs based on polymers 18 and 19 with a monothienylisoindigo monomeric unit.

\begin{tabular}{lllll} 
compound & $V_{\mathrm{OC}}, \mathrm{V}$ & $J_{\mathrm{SC}}, \mathrm{mA} / \mathrm{cm}^{2}$ & $\mathrm{FF}, \%$ & $\mathrm{PCE}, \%$ \\
\hline 18a & 0.97 & 2.72 & 53.1 & 1.40 \\
$\mathbf{1 8 b}$ & 0.94 & 1.93 & 50.0 & 0.91 \\
$\mathbf{1 9 a}$ & 0.73 & 13.92 & 50.2 & 5.10 \\
19b & 0.87 & 4.11 & 63.4 & 2.30
\end{tabular}

Strengthening the donor effect of the monomer unit can be achieved by lengthening the thiophene chain up to three fragments [37-41]. In this case, additional possibilities arise for fine-tuning the properties of polymers due to the introduction of substituents of different structures in each of the thiophene rings. Using the example of OSCs consisting of a mixture of a polymer 25 and $\mathrm{PC}_{71} \mathrm{BM}(1: 1.5, \mathrm{w} / \mathrm{w})$, the effect of the length of the alkyl radical on the efficiency of such cells was shown [37]. Thus, the hexyl and octyl derivatives $25 \mathbf{a}, \mathbf{b}$ showed the best PCE values of 5.1 and 5.2\%, respectively, which is higher than analogues bearing a longer or branched hydrocarbon chain (Scheme 15 and Table 5).

If the OSC active layer is prepared with the addition of diiodooctane, the PCE of the octyl analogue $25 \mathbf{b}$ increases to $6.4 \%$ [38]. A slight change in the substituent at the nitrogen atom and the introduction of electron-donor methyl or electronacceptor cyano groups in the thiophene fragment can lead to a sharp deterioration of all characteristics (structure 26: efficiency $1.94 \%$ ) [39] or to their significant improvement (structure 27, efficiency $8.36 \%$ ), respectively [40]. As it was found, the OSC based on polymer 27 showed one of the best values

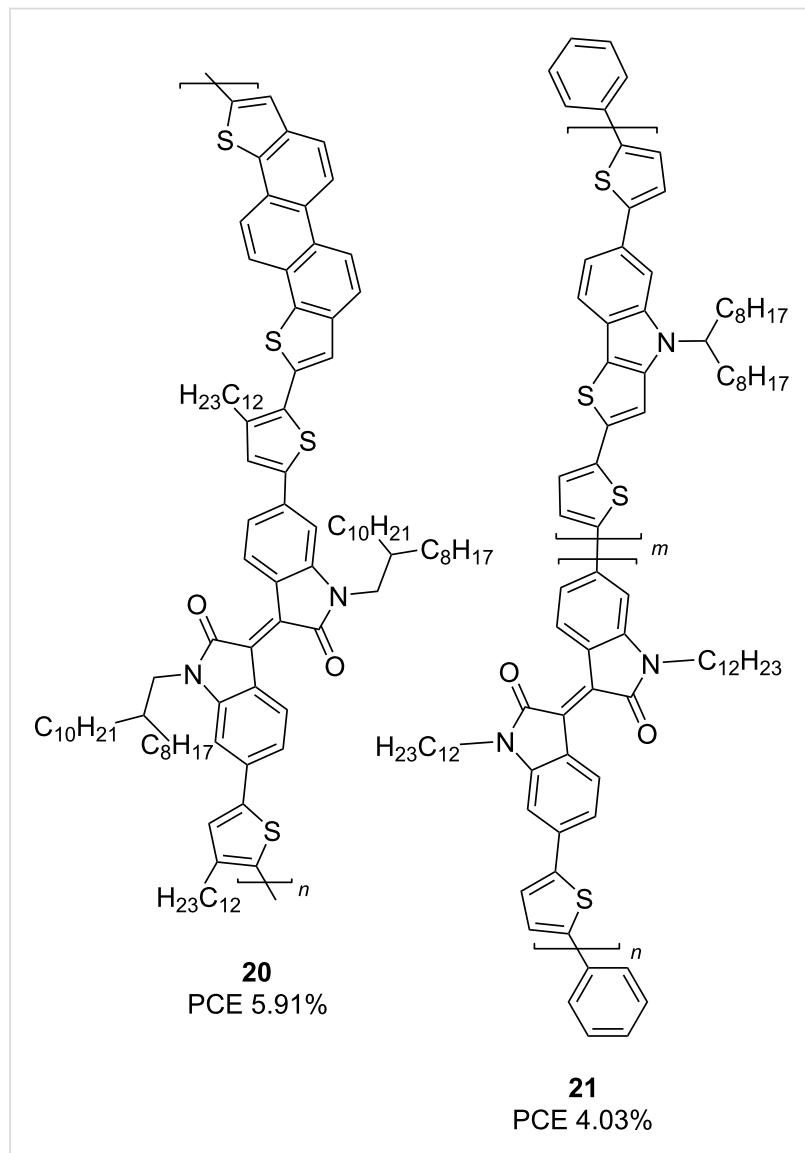

Scheme 13: Monothienylisoindigos bearing m-extended electron-donor backbones.

among the described structures of $V_{\mathrm{OC}} 1.06 \mathrm{~V}$. Others types of polymer structures that have good potential in organic photovoltaics can be found in the form of derivatives $\mathbf{2 8}$ and $\mathbf{2 9}$, 
Table 4: Molecular weight and photovoltaic properties of OSCs based on polymers 22-24

\begin{tabular}{|c|c|c|c|c|c|c|}
\hline compound & $\mathrm{R}$ & $\mathrm{MW}, \mathrm{kDa}$ & $V_{\mathrm{OC}}, \mathrm{V}$ & $J_{\mathrm{SC}}, \mathrm{mA} / \mathrm{cm}^{2}$ & FF, \% & PCE, \% \\
\hline $22 a$ & $\mathrm{H}$ & 45.8 & 0.87 & 8.51 & 61.9 & $4.58^{a}$ \\
\hline $22 b$ & $\mathrm{~F}$ & 75.9 & 1.01 & 9.11 & 67.2 & $6.21^{a}$ \\
\hline $23 a$ & $\mathrm{H}$ & 79.2 & 0.89 & 9.21 & 60.0 & 4.92 \\
\hline $23 b$ & $\mathrm{~F}$ & 91.6 & 1.06 & 12.58 & 66.0 & 8.80 \\
\hline $24 a$ & - & not given & 0.79 & 3.34 & 44.0 & 1.66 \\
\hline $24 b$ & - & not given & 0.60 & 1.08 & 29.0 & 0.99 \\
\hline
\end{tabular}

after annealing at $200^{\circ} \mathrm{C}$.

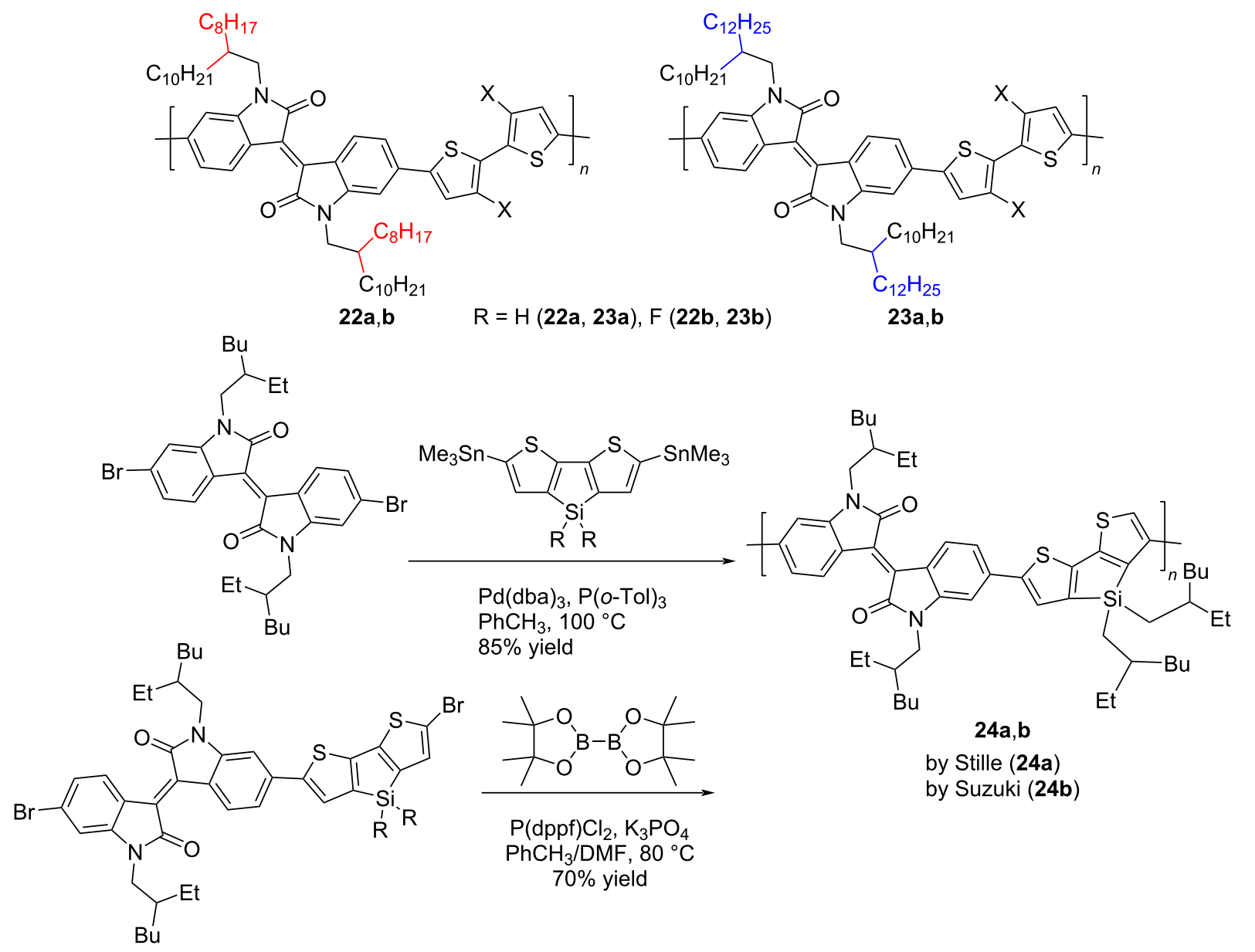

Scheme 14: Role of fluorination and the molecular weight on OSC efficiency on the base of the bithiopheneisoindigo series.

containing two differently substituted isoindigo fragments connected through a thienylene spacer (Scheme 16).

Bini et al. described the synthesis of polymer series $\mathbf{2 8 a}-\mathbf{e}$ with different ratios of isoindigo fragments, one of which is capable of thermal cleavage of Boc groups [42]. Without studying the main characteristics of the OSCs, they showed that after annealing the mixtures of these polymers with $\mathrm{PC}_{61} \mathrm{BM}$ at $200{ }^{\circ} \mathrm{C}$, the surface morphology becomes highly inhomogeneous, with the presence of a large number of crystalline domains. In contrast to the above described study, Liu et al. demonstrated that this type of compounds is promising by 
<smiles>[R]c1cc(-c2ccc3c(c2)N(CC([14CH3])[14CH3])C(=O)/C3=C2/C(=O)N(CC([R16])[CH])c3cc(C(C)(C)C)ccc32)sc1-c1ccc(-c2sc(C(C)(C)C)cc2[R])s1</smiles>

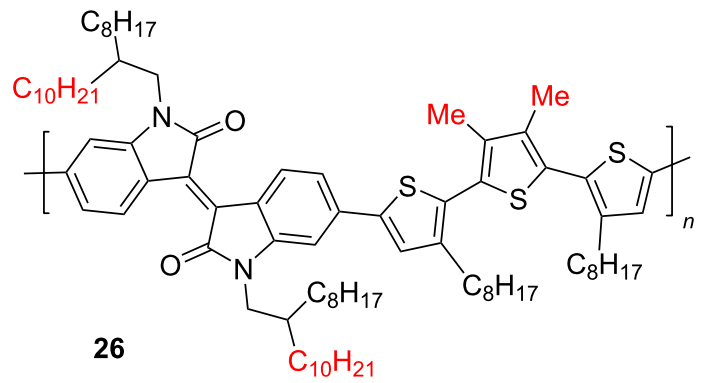

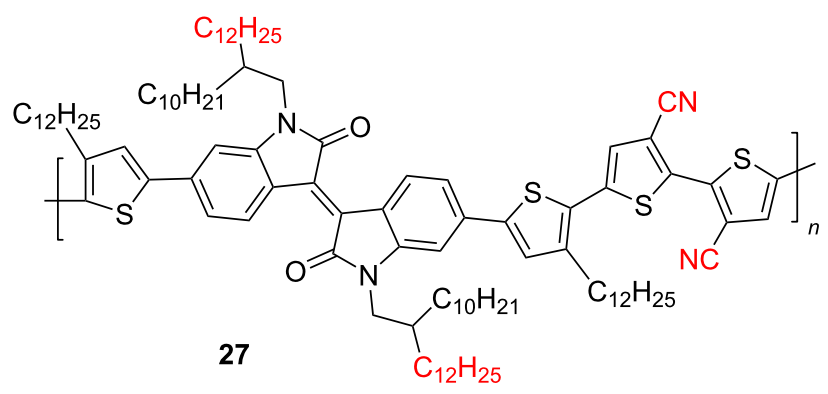

Scheme 15: Trithiopheneisoindigo polymers with variation in the substituent structure.

Table 5: Photovoltaic characteristics of OSCs based on polymers 25-27.

\begin{tabular}{|c|c|c|c|c|c|}
\hline compound & $\mathrm{R}$ & $V_{\mathrm{OC}}, \mathrm{V}$ & $J_{\mathrm{SC}}, \mathrm{mA} / \mathrm{cm}^{2}$ & $\mathrm{FF}, \%$ & PCE, \% \\
\hline $25 a$ & $n$-hexyl & 0.69 & 12.3 & 58.0 & 5.1 \\
\hline $25 b$ & n-octyl & 0.70 & 12.7 & 57.0 & 5.2 \\
\hline $25 c$ & n-decyl & 0.63 & 11.6 & 54.0 & 4.1 \\
\hline $25 d$ & n-dodecyl & 0.69 & 11.3 & 52.0 & 4.0 \\
\hline $25 e$ & 2-ethylhexyl & 0.88 & 0.8 & 58.0 & 0.3 \\
\hline 26 & - & 0.97 & 5.25 & 38.0 & 1.94 \\
\hline 27 & - & 1.06 & 15.7 & 52.0 & 8.36 \\
\hline
\end{tabular}

means of introducing fluorine atoms into the thiophene ring [43]. The use of compound 29c (ratio of monomer units $n / m=$ $2: 1)$ as an acceptor component of the OSC made it possible to achieve one of the highest efficiency values of $7.3 \%$. The problem of the low solubility of such polymers was partially solved by inserting an alkylene spacer between two thiophene fragments in one of the monomer units [44]. Efficiency (3.0-3.7\%) and viscosity characteristics provide good prerequisites for the use of this type of polymers in the design of flexible OSCs.

Condensed thienothiophene substituents can also be used as the donor component of the monomeric isoindigo unit (Scheme 17). The first data on the use of these compounds as donor components of OSCs (mixed with $\mathrm{PC}_{61} \mathrm{BM}$ ) showed that the technology of preparing a thin film of the active layer is important to achieve the best efficiency value [45]. Thus, the best results using compound $\mathbf{3 0}$ (efficiency 2.24\%) were shown by a cell with an active layer of $44 \mathrm{~nm}$ obtained by shifting the solution along the substrate at a rate of $0.1 \mathrm{~mm} / \mathrm{s}$. Compared to compound 30, OSCs based on more complex condensed analogs 31 containing a heterocyclic fragment showed a 2-times better efficiency (5.6\% for difluorothiophene, $5.0 \%$ for selenophene) [46].

The effect of the length and branching of the alkyl substituent at the endocyclic nitrogen atom in a series of this type of donor polymers was investigated. The 2-hexyldecyl derivative exhibited the best compatibility with $\mathrm{PC}_{71} \mathrm{BM}$, which resulted in a high PCE value $(6.83 \%)$ of the corresponding OSC [47]. This efficiency may be due to the good surface morphology of the composite thin film and, as a consequence, the high shortcircuit current $\left(J_{\mathrm{SC}}=13.55 \mathrm{~mA} / \mathrm{cm}^{2}\right)$. It is interesting to note 


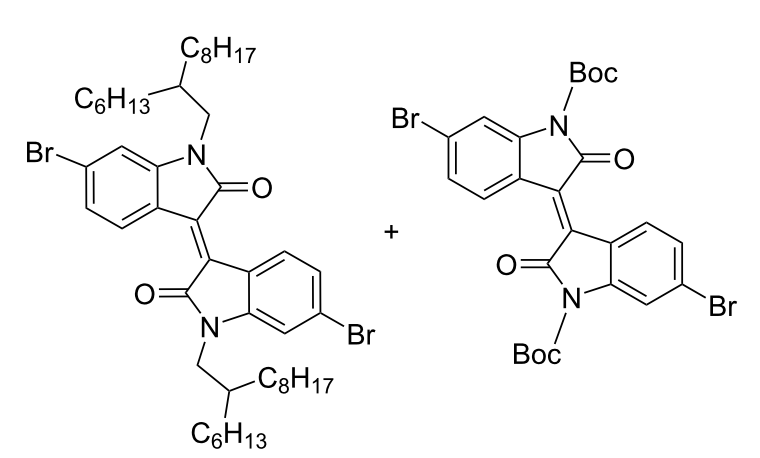<smiles>CCCCCCCc1cc(-c2sc(S(C)(=O)=O)cc2CCCCCC)sc1S(C)(=O)=O</smiles>

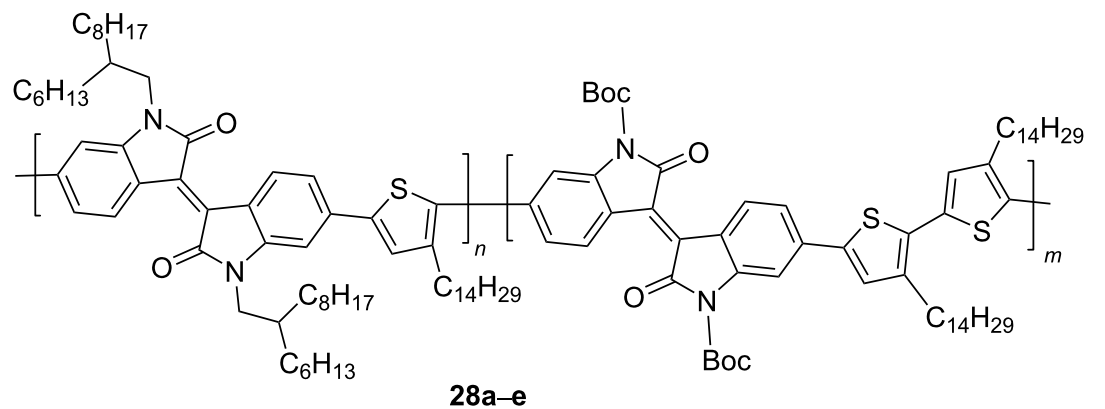

28a $n / m$ 1:0 (59\% yield) 28b $\mathrm{n} / \mathrm{m}$ 0.9:0.1 (65\% yield) 28c $n / m$ 0.8:0.2 (62\% yield) 28d $n / m$ 0.5:0.5 (43\% yield) 28e $n / m$ 0:1 (41\% yield)

$28 a-e$

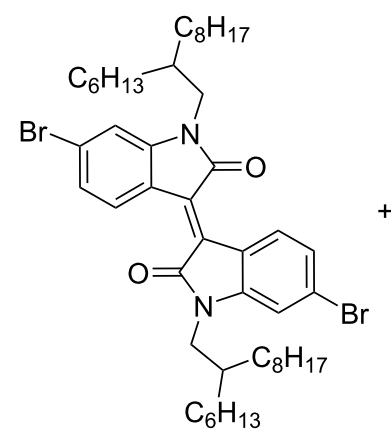

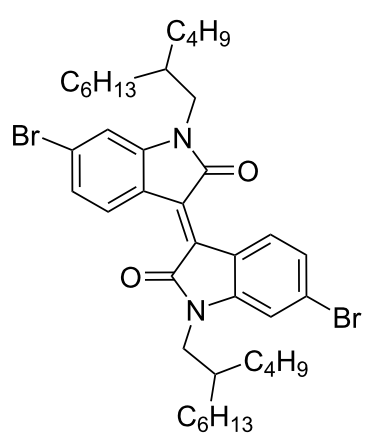<smiles></smiles>

$\mathrm{P}(\mathrm{dba})_{3}, \mathrm{P}(\mathrm{o}-\mathrm{Tol})_{3}$ $\mathrm{mW}$

29a $n / m$ 1:0 (95\% yield)

29b $\mathrm{n} / \mathrm{m} 0: 1$ ( $38 \%$ yield)

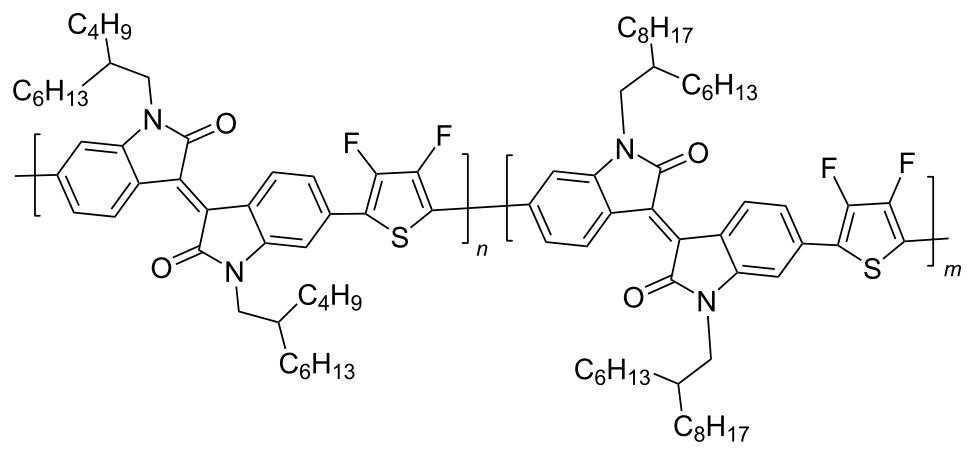

the direction in which isoindigo polymers are used in the design of ternary systems of the OSC active layer. Thus, an OSC consisting of a composite based on two donor polymers (D1 and D2) and an acceptor component $\mathrm{PC}_{71} \mathrm{BM}$ (A) with a D/A weight ratio of 1:4 showed an efficiency of $7.69 \%$ with a D1 content of $15 \%$ relative to the $\mathrm{D} 2$ weight. It should be espe- cially noted that the efficiency of the cell without isoindigo D1 was $6.91 \%$.

To increase the degree of conjugation in the structure of polymeric isoindigo, an introduction of additional aromatic fragments either into the main monomeric chain (compounds of 


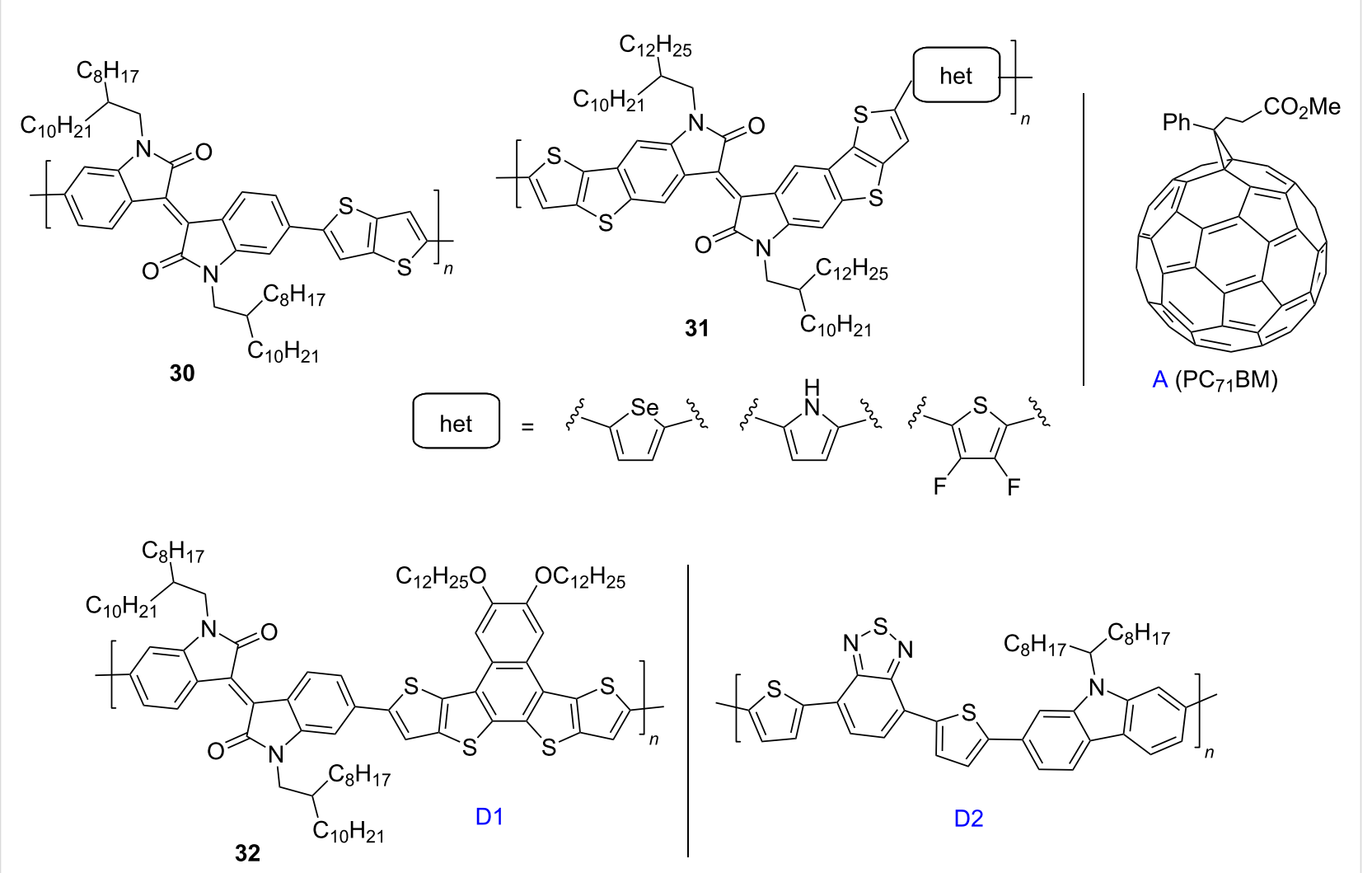

Scheme 17: Isoindigo bearing the thieno[3,2-b]thiophene structural motif as donor component of OSCs.

type 33) [48-50] or as a side substituent in a thiophene unit (compounds of type 34) [51-53] was proposed. Among a number of compounds 33 , the best efficiency (5.29\%) was shown by an OSC based on a mixture of $\mathrm{PC}_{71} \mathrm{BM}$ and polymer 33c containing a short $n$-butyl substituent at the isoindigo nitrogen atoms and the longest and most branched alkyl radical in the p-phenylene fragment (Scheme 18).
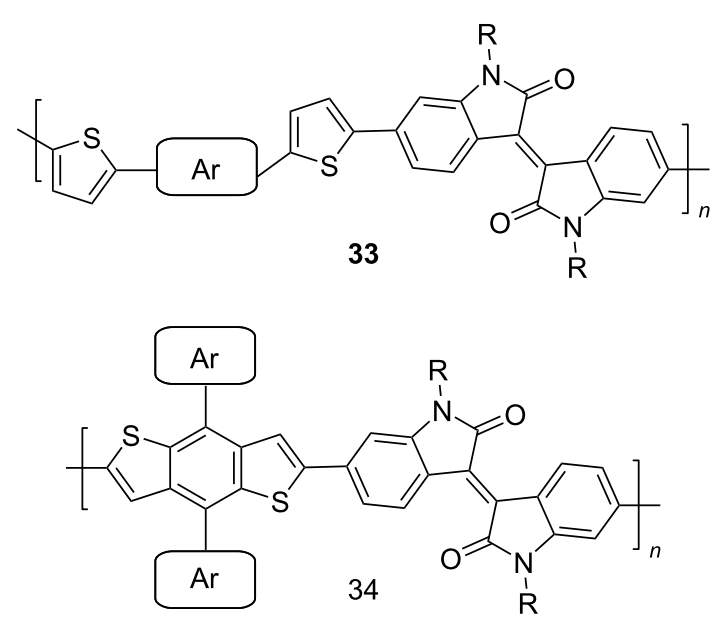

Scheme 18: Thienylisoindigos with incorporated aromatic unit.
Sun et al. showed that such a combination of substituents provides the best miscibility of the polymer with the acceptor fullerene component, which accordingly improves the morphological and photophysical characteristics of the OSC [50]. For comparison, it should be noted that the OSC based on phenanthroquinoxaline derivative 33d showed an efficiency of only $0.3 \%$. The study of composites based on mixtures of compounds 34 with $\mathrm{PC}_{71} \mathrm{BM}$ demonstrated the advantages of the presence of an alkoxyphenyl substituent in the side chain, providing an efficiency of $5.23 \%$. Therein, the presence of a substituent in the phenylene fragment is also an important factor (Table 6). Thus, an OSC based on a fluorine-containing polymer showed an efficiency of only $0.93 \%$. This may be due to the low hole conductivity, a decrease in the HOMO level of the polymer, and a narrower band gap of visible light absorption [51].

Within the framework of the study of the prospects for polymer derivatives of isoindigo in organic photovoltaics and avoiding the use of the fullerene components, the concept of creating one-component OSCs appeared [54]. Following this strategy, isoindigo was used as platform for the synthesis of compound 35a, combining acceptor (perylene diimide) and donor (polythiophene) fragments in the structure. Both polymers were ob- 
tained using the Stille cross-coupling reaction (Scheme 19). However, the OSC of such a cell showed an efficiency of only $1 \%$. Using polymeric isoindigo $\mathbf{3 5} \mathbf{b}$ as an acceptor component, a nonfullerene OSC was also obtained, which showed a record efficiency of $12.03 \%$ among the composites based on isoindigo described to date [55].
Polymeric derivatives of isoindigo containing no thiophene units were also used as acceptor components of the OSCs. Moreover, in both of the studies described in recent years, the donor component of the photovoltaic cell was variously substituted polythiophene, while the acceptor component (isoindigo platform) was functionalized with aromatic nitrogen-containing

Table 6: Photovoltaic characteristics of OSCs based on aromatic embedded polymers $\mathbf{3 3}$ and $\mathbf{3 4}$.

$V_{\mathrm{OC}}, \mathrm{V} \quad J_{\mathrm{SC}}, \mathrm{mA} / \mathrm{cm}^{2} \quad \mathrm{FF}, \%$

PCE, \%

$33 a$

$33 b$

$33 c$

33d

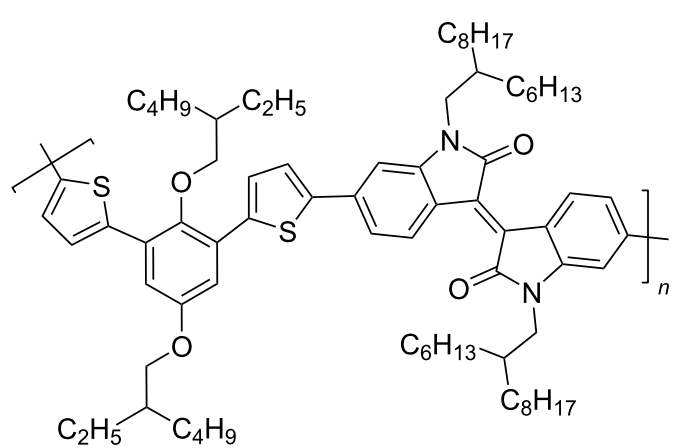

0.71

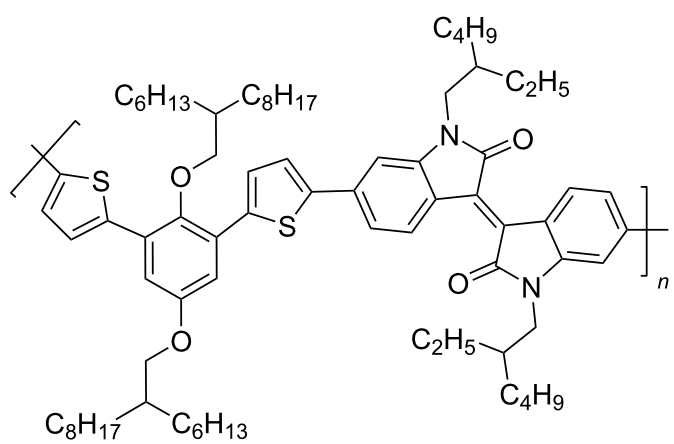

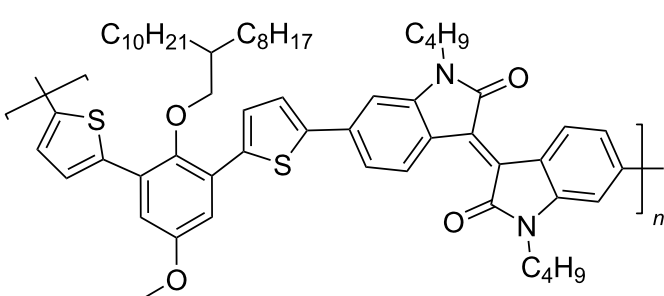<smiles>CCCCC(CC)CCC</smiles>

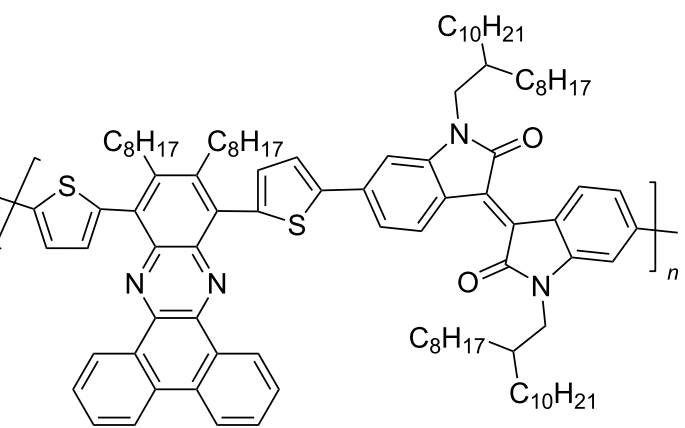


Table 6: Photovoltaic characteristics of OSCs based on aromatic embedded polymers $\mathbf{3 3}$ and $\mathbf{3 4}$. (continued)

$34 a$

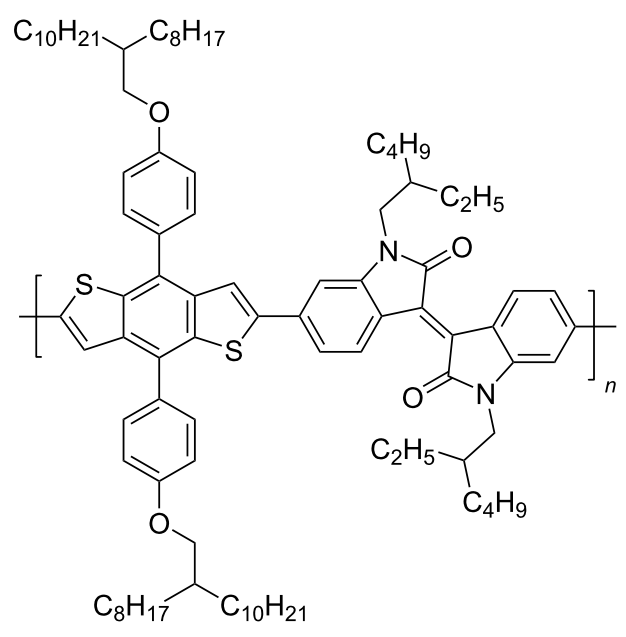

$34 b$

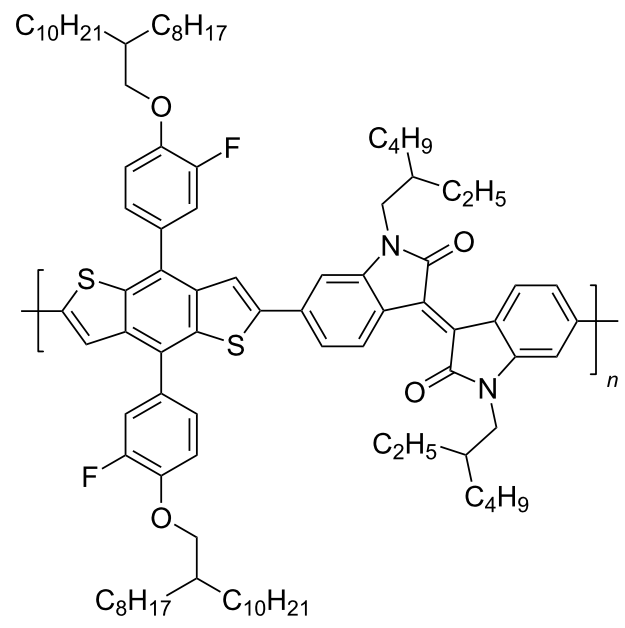

$34 c$

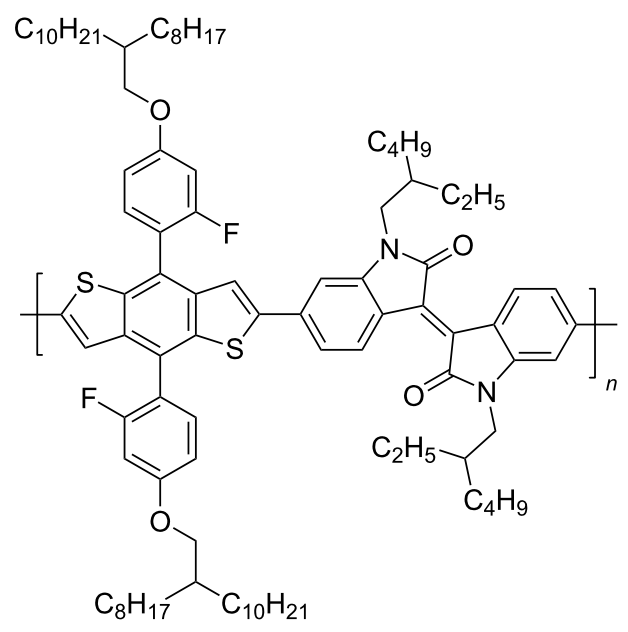




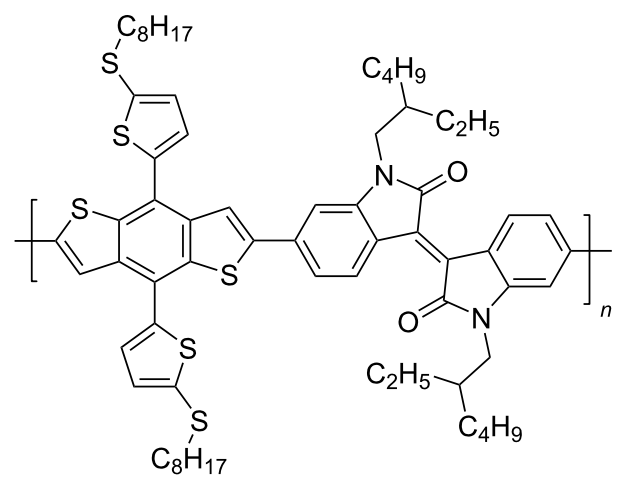

substituents of various structures (Scheme 20). The design of DPP copolymers of isoindigo 37 seems to be the most promising here [56] since OSCs based on it showed a higher efficiency than with compound 36 (4.2 vs $0.26 \%$ ) [57].

Considering the indigoid bisheterocycle as an additional photon trap, the substituted isoindigo was introduced as an acceptor substituent in the structure of the polyconjugated thiophene polymer 38 [58]. For this purpose, two indacenothiophene polymers were obtained containing one or two isoindigo fragments (the position of the introduction of the second isoindigo fragment is indicated by an arrow, Scheme 21). However, the efficiency of the cell based on the monoindigo derivative turned out to be slightly higher (2.66 vs $2.50 \%$ ).

\section{Isoindigo as the basis for organic field-effect transistors (OFET)}

In recent years, the interest of researchers in semiconductor materials has covered the field of organic electronics. The advantages of organic oligomeric and polymeric materials for applications in OFET and thin-film transistor (TFT) technologies are due to the ease of their directed chemical modification, mechanical flexibility, the possibility of varying optoelectronic properties, and good solubility in a wide range of solvents [59-61]. In this regard, the most studied and promising are $\pi$-conjugated polymer structures based on sulfur, oxygen, nitrogen, and selenium heterocyclic compounds $[62,63]$. One of the systems for creating OFET devices is the isoindigo platform [64-68]. Scheme 22 shows polymeric structures with the best mobility values among isoindigo derivatives that are known to date.

Compounds 39-44 are the simplest representatives of isoindigo derivatives used in the design of OFET devices (Scheme 23). In a series of compounds of this type, the central platform of isoindigo is substituted in positions 6,6' either by a phenyl or by a substituted thiophene fragment. Thus, Ashizawa et al. [69] established the ambipolar character of the conductivity of $6,6^{\prime}$-diphenylisoindigo with $\mu_{\mathrm{h}} / \mu_{\mathrm{e}}=0.037 \mathrm{~cm}^{2} \cdot \mathrm{V}^{-1} \cdot \mathrm{s}^{-1} /$ $0.027 \mathrm{~cm}^{2} \cdot \mathrm{V}^{-1} \cdot \mathrm{s}^{-1}$. Although the obtained values of mobility turned out to be low, this finding could have contributed to the development of this direction by the design of electron-donating aromatic substituents at the isoindigo core. However, as was shown in subsequent works, neither a change in the length and structure of the thiophene chain, nor the presence of an embedded benzothiadiazole fragment led to an improvement in the characteristics of transistors based on compounds 39-43 [7073]. These derivatives had only hole-type conductivity in the range $\mu_{\mathrm{h}}=1.5 \cdot 10^{-4}-6 \cdot 10^{-6} \mathrm{~cm}^{2} \cdot \mathrm{V}^{-1} \cdot \mathrm{s}^{-1}$.

According to the available data, the most studied polymeric isoindigos are dithienyl derivatives, in which two thiophene fragments can be linked to each other [74-86] or be separated by spacers of different structures [87-91]. Structures containing a 2,2'-dithienyl fragment can be divided into three types: 1) not containing substituents in the benzo and thienyl fragments; 2) containing fluorine atoms in the thienyl fragment; and 3) containing fluorine atoms in positions $7,7^{\prime}$ and in thienyl fragments (Scheme 24).

Studies of the characteristics of OFETs based on compounds $\mathbf{4 5}$ showed almost complete absence of a dependence of the semiconductor properties $\left(\mu_{\mathrm{e}}=0.08-0.01 \mathrm{~cm}^{2} \cdot \mathrm{V}^{-1} \cdot \mathrm{s}^{-1}\right)$ on the structure of the alkyl substituent at the nitrogen atom. It was only established that the distancing of the branching position of the alkyl chain affects the ordering of molecules in a thin polymer film after annealing [83]. At the same time, for the example of polymer 45 containing a 4-decyltetradecyl radical, it was shown that the efficiency of an OFET device depends on the method of thin film processing. In contrast to the traditional spin-coating technique, the authors succeeded in obtaining a thin film by 


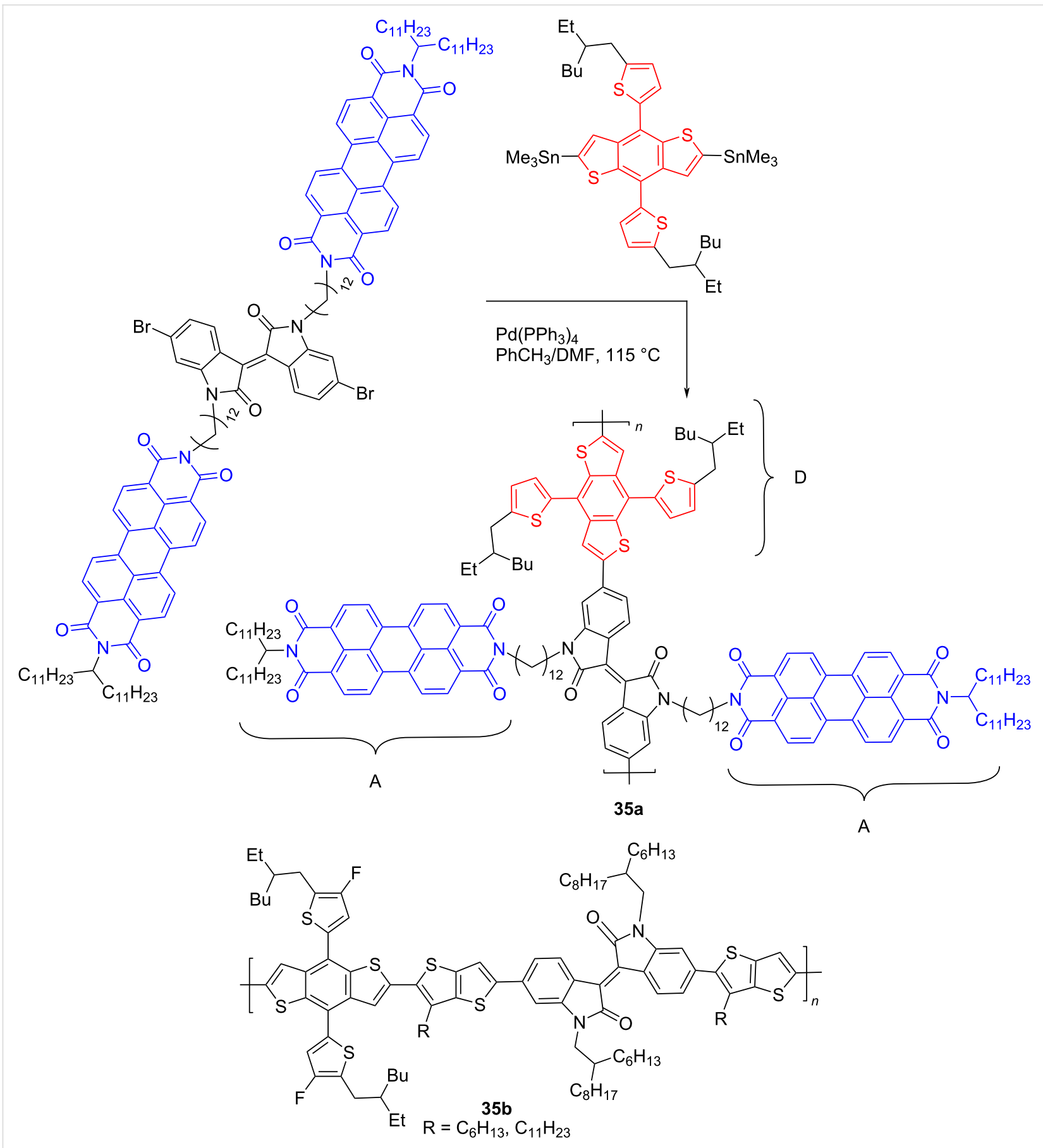

Scheme 19: One-component nonfullerene OSCs on the base of isoindigo.

immersing a substrate in a polymer solution, followed by slow extraction, accompanied by slow evaporation of the solvent. The device thus obtained showed one of the highest values of hole conductivity of $\mu_{\mathrm{e}}=8.3 \mathrm{~cm} \mathrm{~cm}^{2} \cdot \mathrm{V}^{-1} \cdot \mathrm{s}^{-1}$ [78]. It was also found that a device based on compound 45 ( $\mathrm{R}=2$-decyltetradecyl) with the addition of iron phthalocyanine showed slightly better mobility. Liu et al. explain this effect by an improvement in the hole-type conductivity and a tight and even packing of the composite in a thin film [80]. At the same time, selenophene analogs generally show lower values of mobility [90]. The introduction of fluorine atoms into the dithienyl fragment (see compound 46), while varying the symmetry of substitution of the 1,1 ' positions in isoindigo, did not lead to an improvement in the OFET efficiency (maximum $\mu_{\mathrm{h}}=1.08 \mathrm{~cm}^{2} \cdot \mathrm{V}^{-1} \cdot \mathrm{s}^{-1}$ ). For comparison, a similar device based on a nonfluorinated analog showed a value of $\mu_{\mathrm{h}}=2.71 \mathrm{~cm}^{2} \cdot \mathrm{V}^{-1} \cdot \mathrm{s}^{-1}$ [74]. Continuing the 


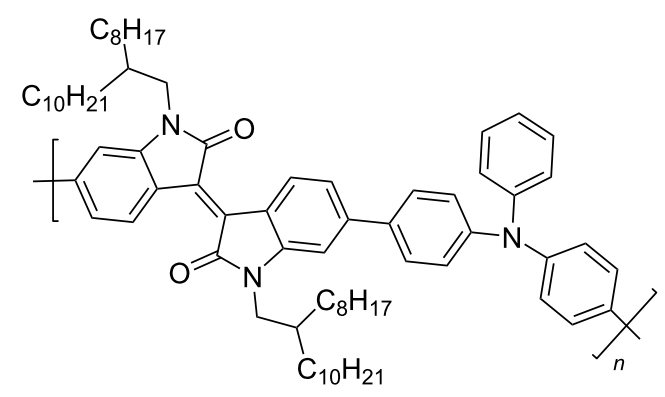

36

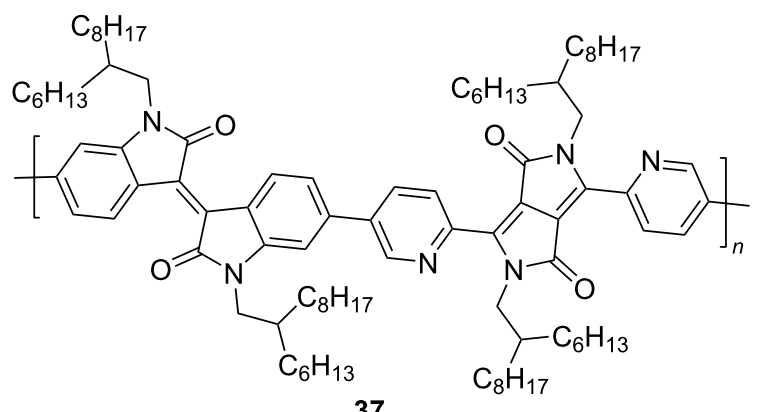

37

Scheme 20: Isoindigo-based nonthiophene aza aromatic polymers as acceptor components of OSCs.

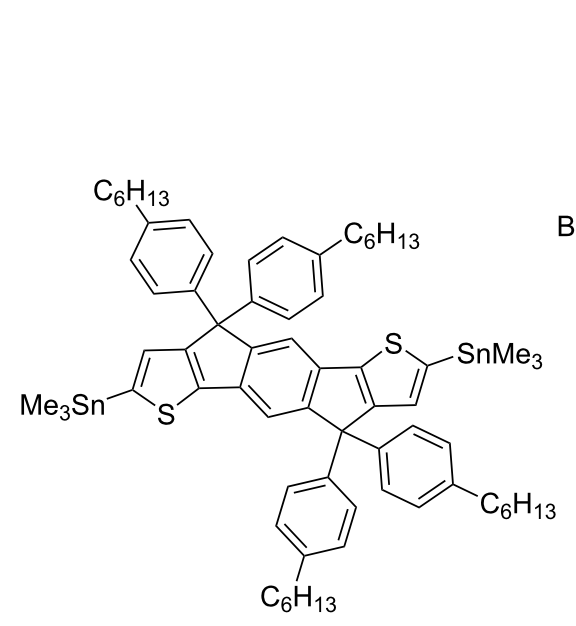<smiles></smiles>

$\mathrm{Pd}(\mathrm{dba})_{3}, \mathrm{P}(\mathrm{o}-\mathrm{Tol})_{3}$

$\mathrm{PhCH}_{3}, 110^{\circ} \mathrm{C}$

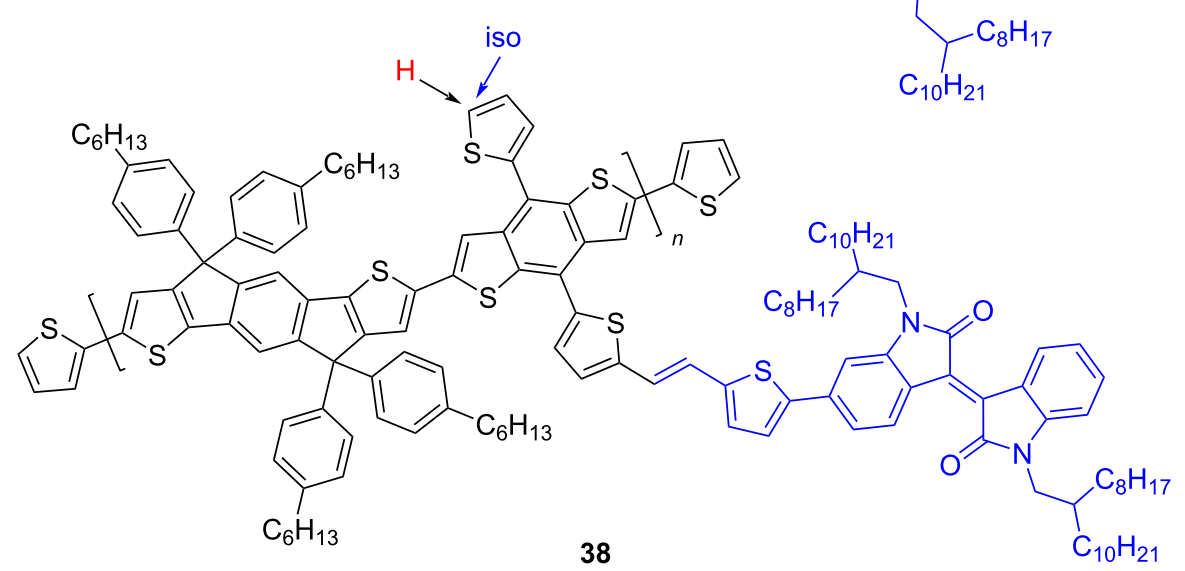

Scheme 21: Polymers with isoindigo substituent as side-chain photon trap.

study of the effect of the substituent nature on the OFET efficiency, a number of polymers $\mathbf{4 7}$ with varying degree of fluorination of the monomer structural units was obtained [79]. The study showed that the transition from a less fluorinated analogue (two fluorine atoms on dithiophene) to one containing a larger number of fluorine atoms (two fluorine atoms on dithio- phene and two in the 7,7' positions) improves the planarity of the structural units of the polymer and increases the degree of crystallinity, which consequently increases $\mu_{\mathrm{e}}$. At the same time, the polymer containing two fluorine atoms on the dithiophene unit and one in position 7 exhibited balanced ambipolar properties, having the currently best ratio of 


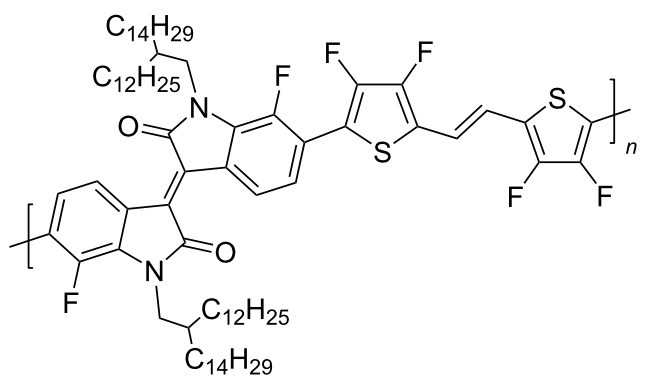

$\mathrm{P} 6 \mathrm{~F}$ $\mu_{\mathrm{h}} / \mu_{\mathrm{e}}=3.94 \mathrm{~cm}^{2} \cdot \mathrm{V}^{-1} \cdot \mathrm{s}^{-1} / 3.50 \mathrm{~cm}^{2} \cdot \mathrm{V}^{-1} \cdot \mathrm{s}^{-1}$

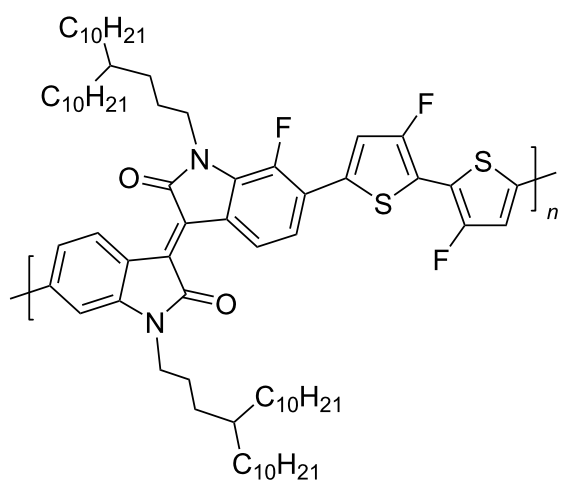

P1FIID-2FBT $\mu_{\mathrm{h}} / \mu_{\mathrm{e}}=6.41 \mathrm{~cm}^{2} \cdot \mathrm{V}^{-1} \cdot \mathrm{s}^{-1} / 6.76 \mathrm{~cm}^{2} \cdot \mathrm{V}^{-1} \cdot \mathrm{s}^{-1}$

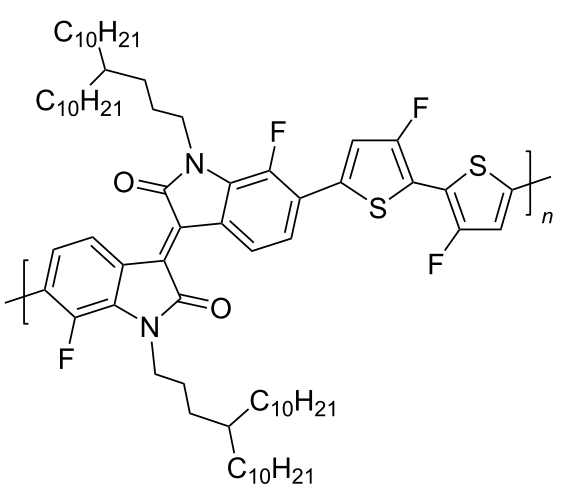

P2FIID-2FBT

$\mu_{\mathrm{e}}=9.70 \mathrm{~cm}^{2} \cdot \mathrm{V}^{-1} \cdot \mathrm{s}^{-1}$

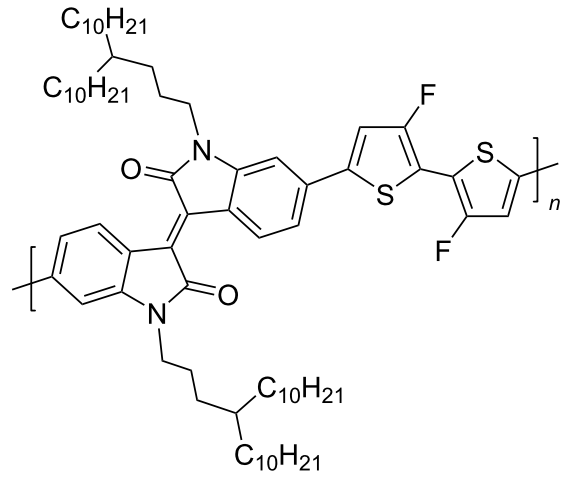

PIID-2FBT

$\mu_{\mathrm{h}} / \mu_{\mathrm{e}}=5.33 \mathrm{~cm}^{2} \cdot \mathrm{V}^{-1} \cdot \mathrm{s}^{-1} / 2.06 \mathrm{~cm}^{2} \cdot \mathrm{V}^{-1} \cdot \mathrm{s}^{-1}$

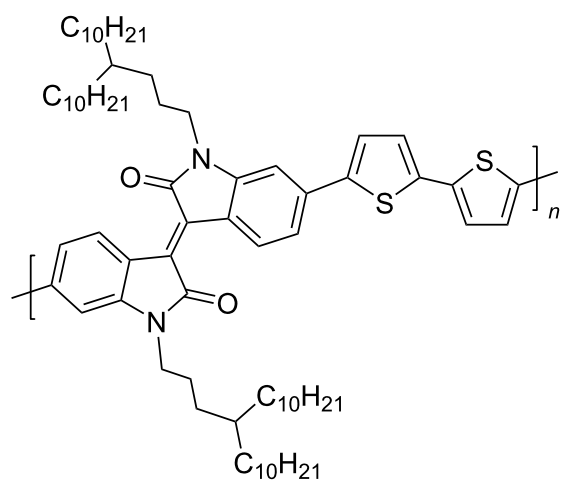

PII-2T

$\mu_{\mathrm{h}}=8.31 \mathrm{~cm}^{2} \cdot \mathrm{V}^{-1} \cdot \mathrm{s}^{-1}$

Scheme 22: Isoindigo derivatives for OFET technology with the best mobility.

$\mu_{\mathrm{h}} / \mu_{\mathrm{e}}=6.41 \mathrm{~cm}^{2} \cdot \mathrm{V}^{-1} \cdot \mathrm{s}^{-1} / 6.46 \mathrm{~cm}^{2} \cdot \mathrm{V}^{-1} \cdot \mathrm{s}^{-1}$ among isoindigoid polymers.

Attempts to improve the efficiency of isoindigo-based OFETs by introducing an ethylene bridge between thiophene fragments in general did not lead to the desired result (Scheme 25).
Thus, devices based on polymers $\mathbf{4 8}$ and 49 showed an analogy in the unipolar character of the conductivity with close values of $\mu_{\mathrm{h}}=0.68-0.83 \mathrm{~cm}^{2} \cdot \mathrm{V}^{-1} \cdot \mathrm{s}^{-1}[87,91]$. It should be noted here that more detailed studies on selenium analogs of polymers $\mathbf{4 8}$ are promising since the latter showed moderate values of electronic mobility of $\mu_{\mathrm{e}}=1.28 \mathrm{~cm}^{2} \cdot \mathrm{V}^{-1} \cdot \mathrm{s}^{-1}$ [89]. It was shown that a sig- 


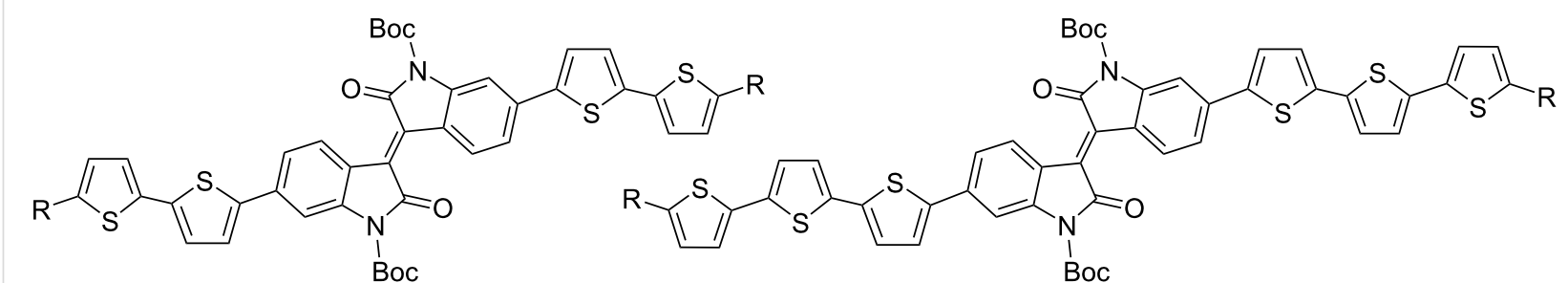

39,40 $\mathrm{R}=\mathrm{H}, n-\mathrm{C}_{6} \mathrm{H}_{13}$

41,42
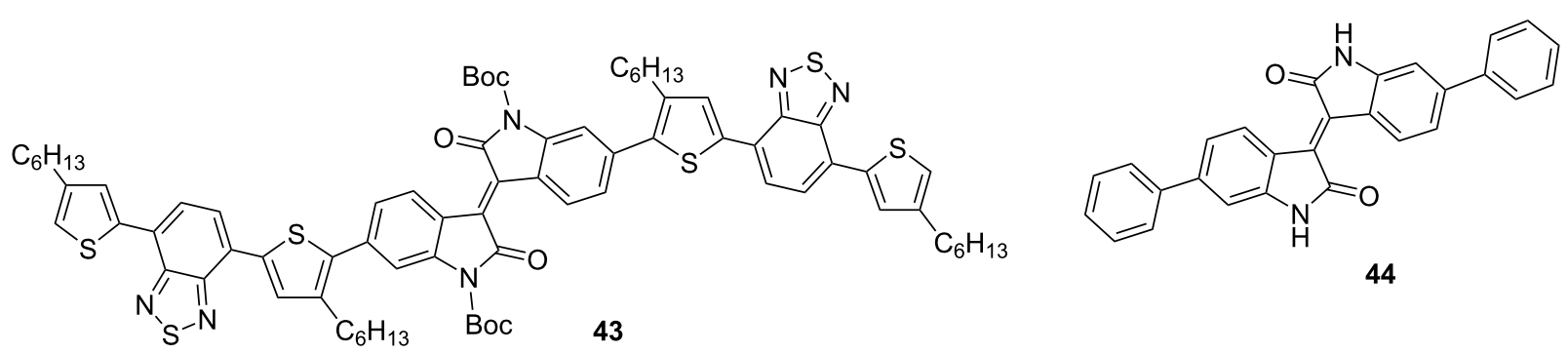

Scheme 23: Monoisoindigos as low-molecular-weight semiconductors.<smiles>[R]N1C(=O)/C(=C2\C(=O)N([R])c3cc(C(C)(C)C)ccc32)c2ccc(-c3ccc(-c4ccc(C(C)(C)C)s4)s3)cc21</smiles><smiles>[X]c1cc(-c2ccc3c(c2)N([R1])C(=O)C3=C2C(=O)N([R])c3cc(C)ccc32)sc1-c1sc(C(C)(C)C)cc1[X]</smiles>

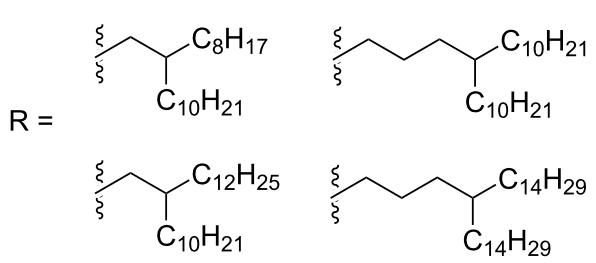

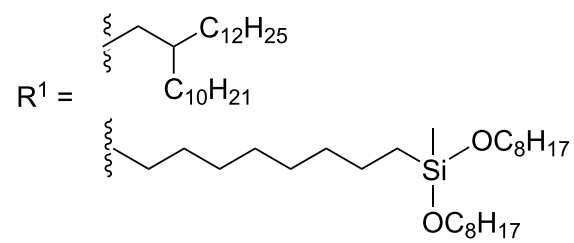<smiles>[R][R]=CCCCCCCCCC[Si](C)(O[Z7])O[R17]</smiles><smiles>CCCCCCCCC[Si](C)(CC)CC</smiles><smiles>[X]c1c(-c2cc(F)c(-c3sc(C(C)(C)C)cc3F)s2)ccc2c1N([R])C(=O)/C2=C1/C(=O)N([R])c2c1ccc(C(C)(C)C)c2[X]</smiles><smiles>[CH]CCCCCC[Si](C)(OCC)O[Si](C)(CCCCCC)OC</smiles><smiles>CCCCCCCC[Si](C)(CC)CCC</smiles><smiles>CCCCCCCC[Si](C)(OCC)OCC</smiles> 
<smiles>[R]N1C(=O)/C(=C2/C(=O)N([R])c3cc(C(C)(C)C)ccc32)c2ccc(-c3ccc(/C=C/c4ccc(C(C)(C)C)s4)s3)cc21</smiles>

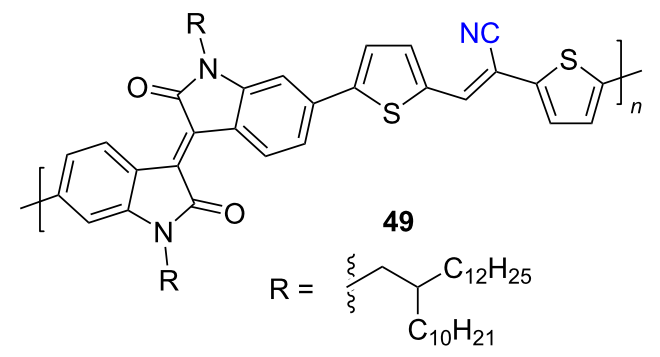<smiles>[X]c1c(C=Cc2sc(C(C)(C)C)c([X])c2[X])sc(-c2ccc3c(c2[X])N([R])C(=O)C3=C2C(=O)N([R])c3c2ccc(C)c3[X])c1[X]</smiles>

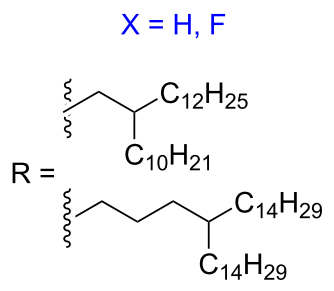

Scheme 25: Fluorination as a tool to improve isoindigo-based OFET devices.

nificant improvement of the semiconducting properties of an isoindigo polymer can be achieved by "multifluorination", the introduction of fluorine atoms both to the dithiophene fragment and to the 7,7'-positions of isoindigo (compound 50) [88]. As such, the presence of fluorine atoms led to the ambipolarity of the polymer with an effective ratio $\mu_{\mathrm{h}} / \mu_{\mathrm{e}}=3.94 \mathrm{~cm}^{2} \cdot \mathrm{V}^{-1} \cdot \mathrm{s}^{-1} /$ $3.50 \mathrm{~cm}^{2} \cdot \mathrm{V}^{-1} \cdot \mathrm{s}^{-1}$.

Recently, diketopyrrolo[3,4-c]pyrrole (DPP) derivatives, which are highly conjugated electron-withdrawing heterocycles with high charge conductivity, broad absorption spectrum, photostability, and thermal stability have attracted considerable interest of researchers in the field of organic electronics [92-94]. Isoindigo derivatives have similar characteristics. Taking into account these data, copolymers $\mathbf{5 1}$ containing up to 25\% DPP units were obtained [95]. Despite the good prerequisites, an OFET based on this copolymer showed only hole-type conductivity with $\mu_{\mathrm{h}}=1.2 \cdot 10^{-3} \mathrm{~cm}^{2} \cdot \mathrm{V}^{-1} \cdot \mathrm{s}^{-1}$. Therein, the thermolysis of a thin film of the device at $220{ }^{\circ} \mathrm{C}$, accompanied by the elimination of Boc groups, led to a significant decrease of the OFET performance. For the example of the polymers 52 series, the importance of the spatial arrangement of the isoindigo and DPP fragments relative to each other was demonstrated [96]. Thus, the dihedral angle $179^{\circ}$ in a furan polymer determines the conductivity $\mu_{\mathrm{h}} / \mu_{\mathrm{e}}=0.01 \mathrm{~cm}^{2} \cdot \mathrm{V}^{-1} \cdot \mathrm{s}^{-1} / 1.6 \cdot 10^{-3} \mathrm{~cm}^{2} \cdot \mathrm{V}^{-1} \cdot \mathrm{s}^{-1}$, while polymers containing thiophene or $p$-phenylene spacers did not possess conductivity at all due to the lower planarity (dihedral angle $143^{\circ}$, Scheme 26, Table 7).

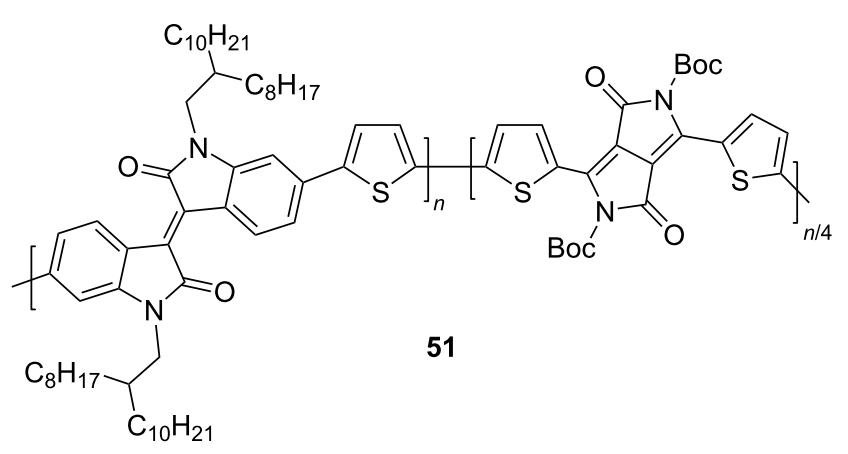

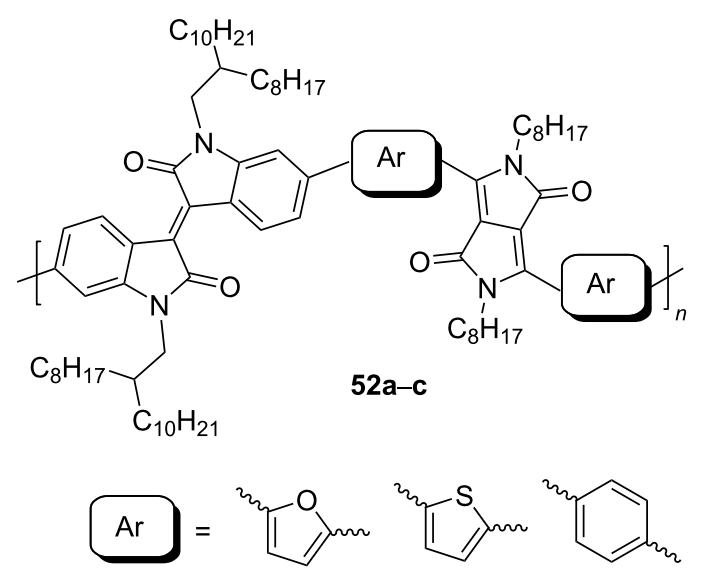


Table 7: Transistor characteristics of DPP-isoindigo-conjugated polymers $\mathbf{5 1}$ and $\mathbf{5 2 .}$

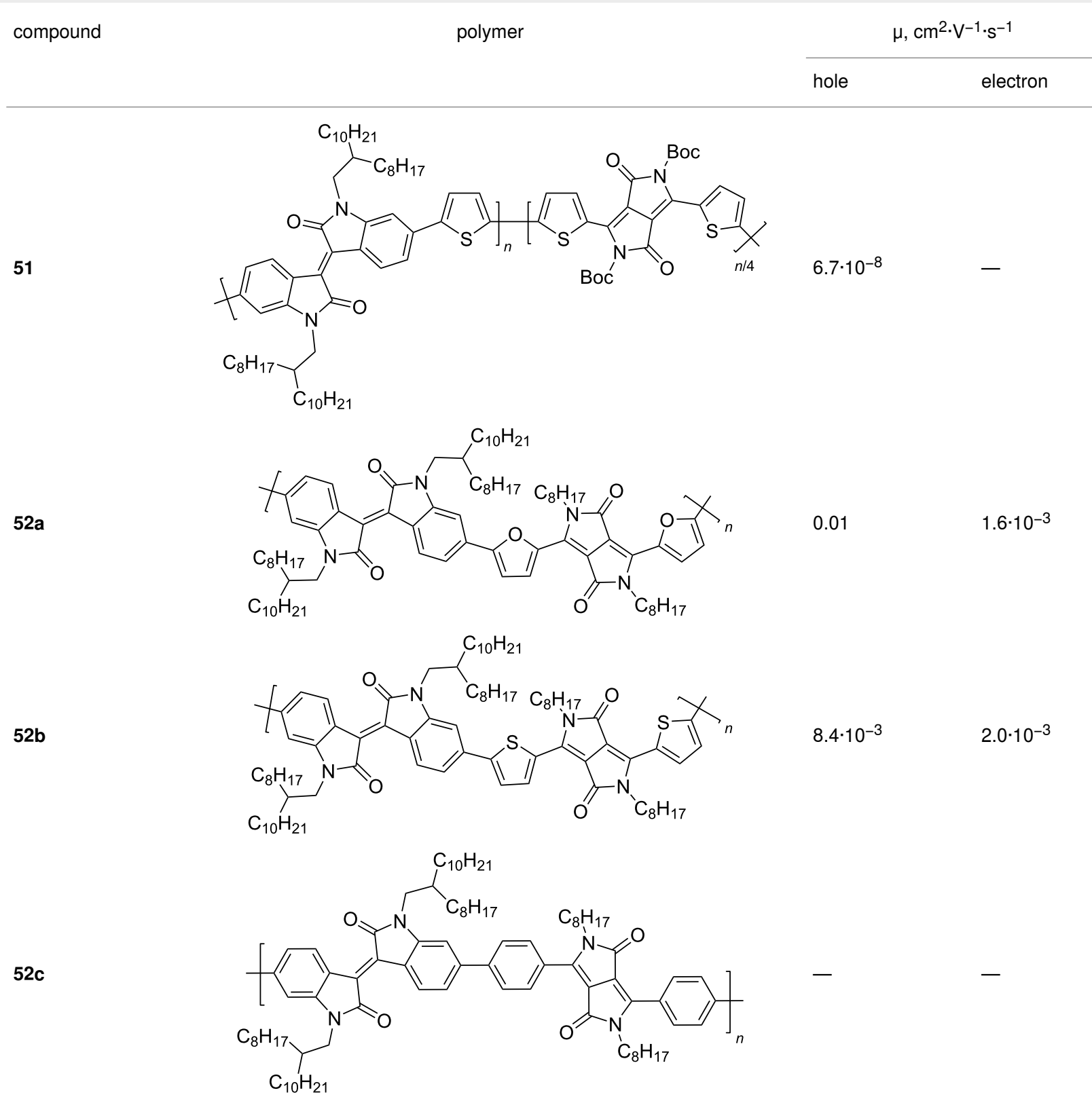

Homopolymers based on isoindigo of various types have also been used in the design of transistors [97-100]. In order to reduce the influence of factors of conformational and energy disordering inherent in all isoindigo polymers in which aromatic fragments are linked by a single bond, a number of homopolymers 53 was obtained by the aldol polycondensation reaction [97]. These compounds have rigid and almost planar structures with a wide absorption range, high electron affinity, good solubility, and ambient stability (Scheme 27). The study of the transistor characteristics showed that these homopolymers have an electronic type of conductivity, with a maximum value of $\mu_{\mathrm{e}}=0.03 \mathrm{~cm}^{2} \cdot \mathrm{V}^{-1} \cdot \mathrm{s}^{-1}$. The work [98] was also aimed at obtaining OFET devices based on homopolymeric isoindigo. The thieno-based condensed polymers $\mathbf{5 4}$ described herein, in which the monomeric isoindigo fragments are linked by a single bond, were obtained in two ways: by Suzuki (40\% yield) and Stille (50\% yield) coupling reactions. Despite the possibility of rotation of monomeric fragments around a single bond, a transistor based on this polymer showed relatively high values of mobility of $\mu_{\mathrm{h}} / \mu_{\mathrm{e}}=0.065 \mathrm{~cm}^{2} \cdot \mathrm{V}^{-1} \cdot \mathrm{s}^{-1} / 0.15 \mathrm{~cm}^{2} \cdot \mathrm{V}^{-1} \cdot \mathrm{s}^{-1}$. It is also worth presenting data on compounds $\mathbf{5 5}$ containing thiophene bridges of various structures between the isoindigo nuclei $[99,101]$. 


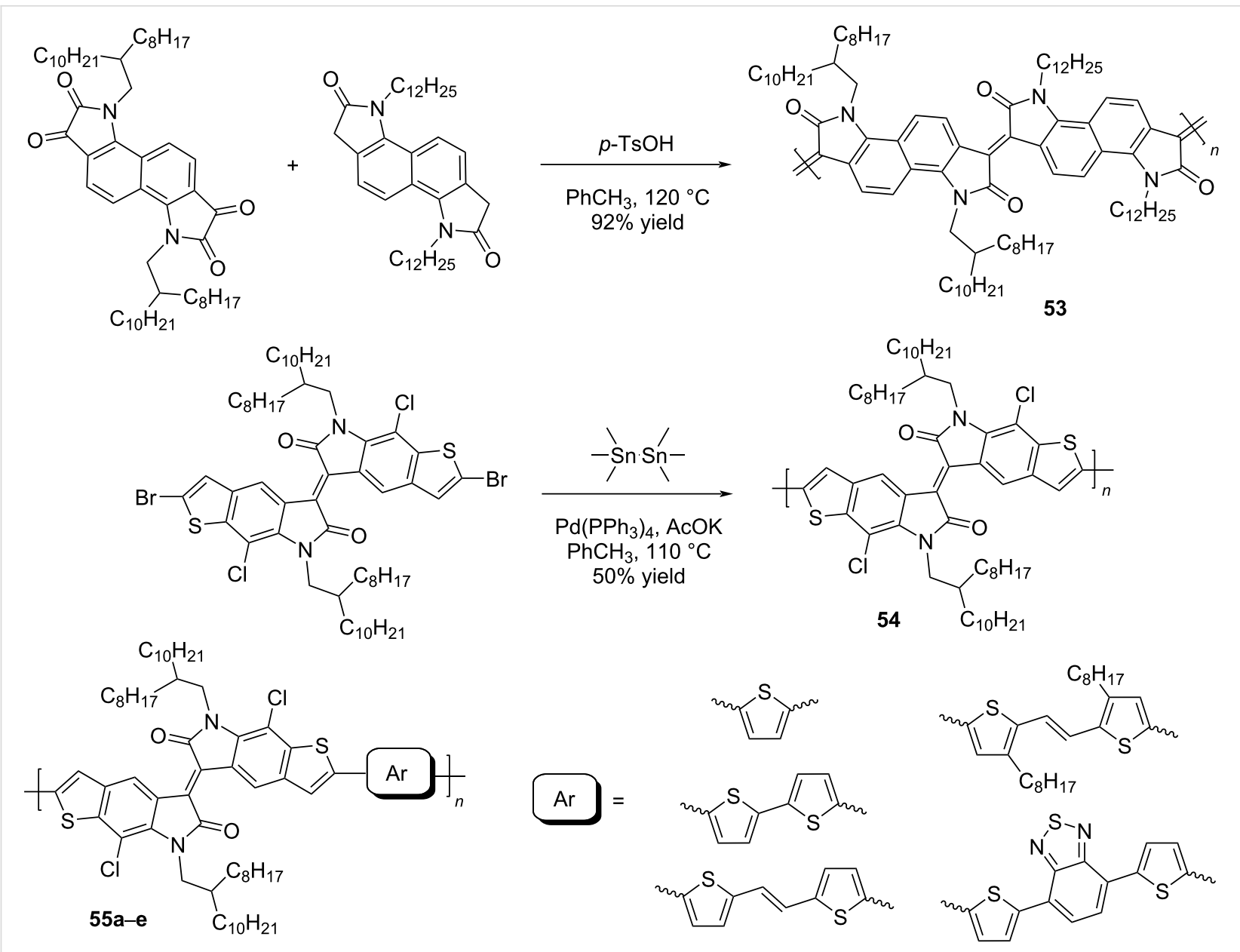

Scheme 27: Isoindigoid homopolymers with differing rigidity.

Therein, the presence of a spacer, in comparison to compounds $\mathbf{5 4}$, led to a decrease of the OFET performance (maximum $\mu_{\mathrm{h}} / \mu_{\mathrm{e}}=0.037 \mathrm{~cm}^{2} \cdot \mathrm{V}^{-1} \cdot \mathrm{s}^{-1} / 0.029 \mathrm{~cm}^{2} \cdot \mathrm{V}^{-1} \cdot \mathrm{s}^{-1}$, Table 8).

One of the directions for the design of polymeric isoindigo derivatives to improve the conductive properties is the lengthening of the conjugation chain of both the monomer unit itself and the monomer subunit [102-105]. Thus, two polymers 56 were obtained in which isoindigo fragments are condensed on the indacenedione scaffold [102]. Despite the presence of an extended $\pi$-conjugation system, which determines the ambipolar properties of a transistor based on these polymers, the charge mobility values turned out to be rather low (Scheme 28). The maximum value of $\mu_{\mathrm{h}} / \mu_{\mathrm{e}}=0.1 \mathrm{~cm}^{2} \cdot \mathrm{V}^{-1} \cdot \mathrm{s}^{-1} / 0.14 \mathrm{~cm}^{2} \cdot \mathrm{V}^{-1} \cdot \mathrm{s}^{-} 1$ was shown by a polymer containing a bridging ethylene fragment between two thiophene substituents. The lengthening of the conjugation chain within the monomeric unit can be achieved by introducing phenylenequinoxaline [103] or fluorinated phenylenethiophene [104] fragments. Based on compound 57, a flexible OFET with $\mu_{\mathrm{e}}=0.25 \mathrm{~cm}^{2} \cdot \mathrm{V}^{-1} \cdot \mathrm{s}^{-1}$ was fabricated on a $3 \mathrm{D}$ printer. In contrast to the above, an OFET based on difluorobenzothiadiazole polymer $\mathbf{5 8}$ showed hole conductivity with a low charge mobility value of $\mu_{\mathrm{h}}=0.07 \mathrm{~cm}^{2} \cdot \mathrm{V}^{-1} \cdot \mathrm{s}^{-1}$.

\section{Isoindigo-based sensor devices}

Isoindigo derivatives have begun to find an application in the design of sensor devices for the detection of simple and complex molecules in various aggregation states. Thus, it was shown that polymer structures based on isoindigo and thiophene 59a,b and 60a,b are able to effectively bind gaseous ammonia molecules (Scheme 29) [106].

Thin films of these polymers are characterized by high sensitivity, reproducibility, and fast response time. Among this series of compounds, polymer $\mathbf{6 0 b}$, containing a terthiophene oligomeric unit, has the best characteristics. Further studies showed that a polymer composite based on the terthiophene analogue 59a, poly(methyl methacrylate), and polyaniline is capable of detecting vapors of some organic solvents 
Table 8: Transistor characteristics of homopolymers 53-55.

compound

polymer

$\mu, \mathrm{cm}^{2} \cdot \mathrm{V}^{-1} \cdot \mathrm{s}^{-1}$
hole electron

53

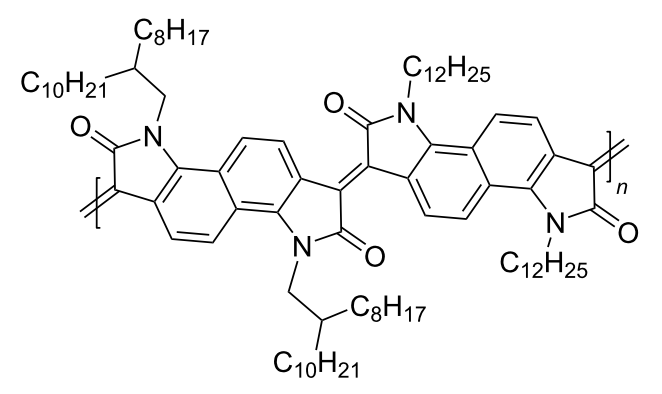

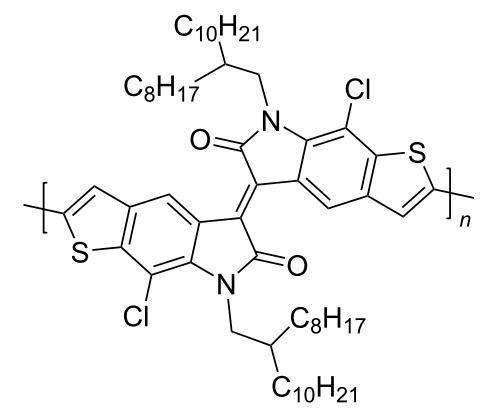

$55 a$

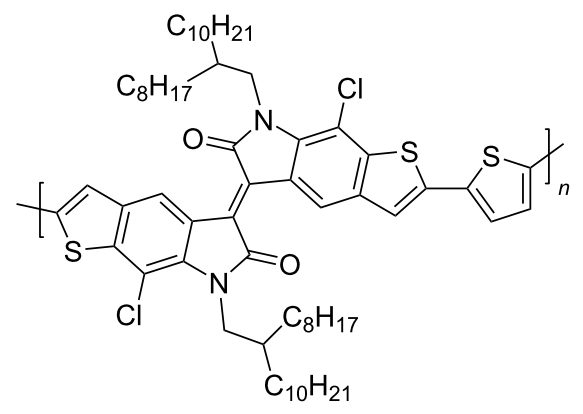

55b

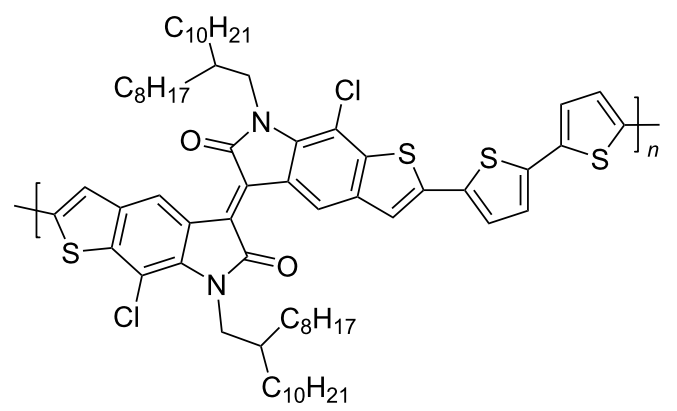

$55 c$

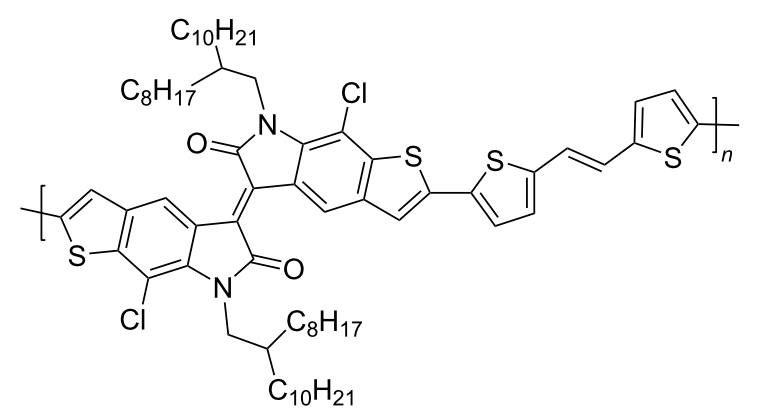


Table 8: Transistor characteristics of homopolymers 53-55. ${ }^{\text {a }}$ (continued)

$55 d$

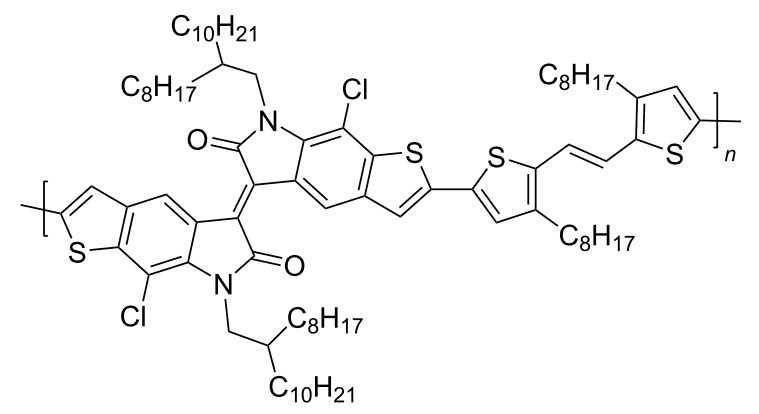

$55 e$

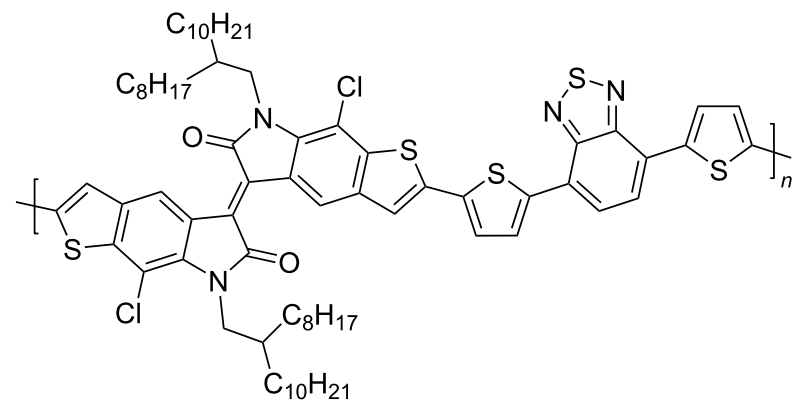

apolymers $\mathbf{5 5 b}, \mathbf{d}, \mathbf{e}$ were not studied due to the low solubility in a wide range of organic solvents.

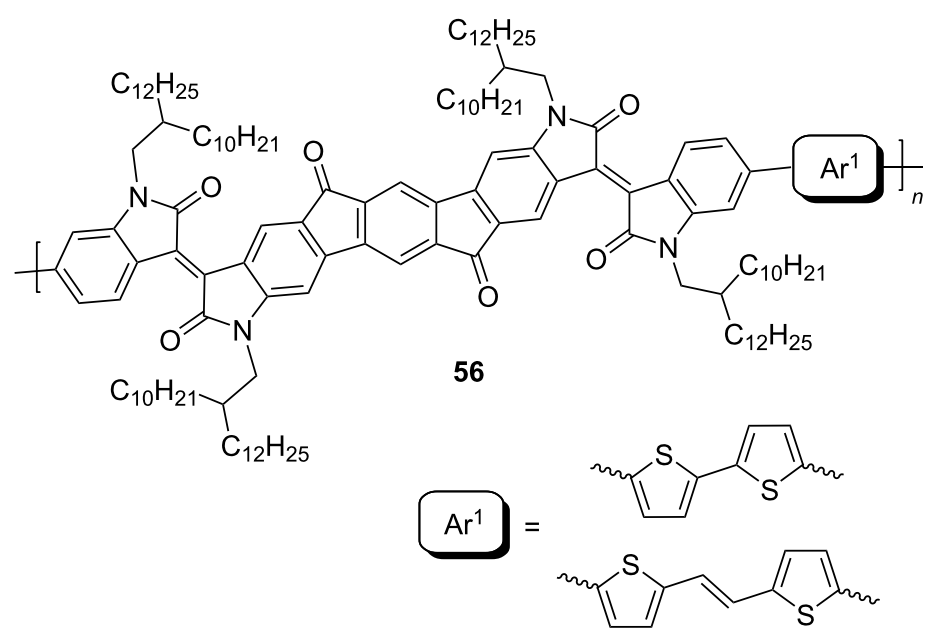

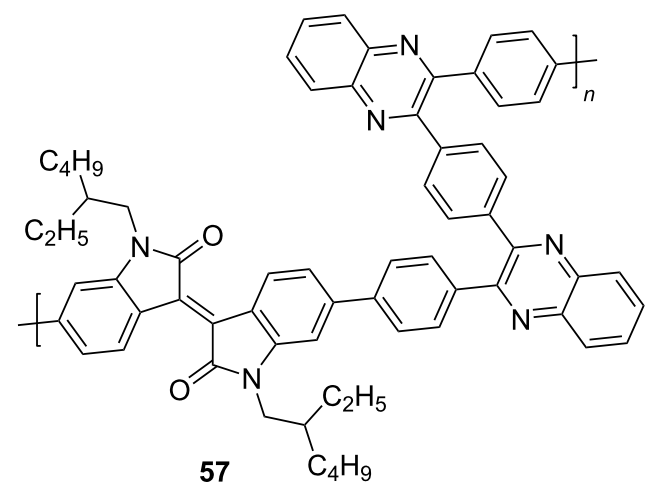

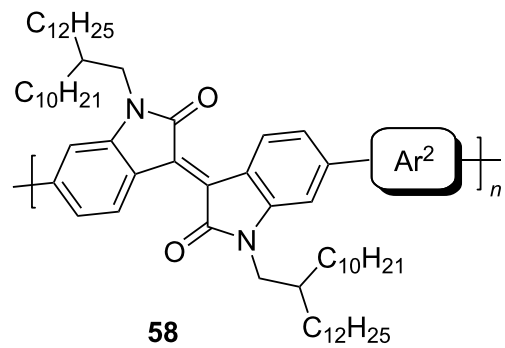<smiles>Cc1ccc(-c2c(F)c(F)c(-c3ccc(C4C5CCC(CC5)[C@H]4F)s3)c3nsnc23)s1</smiles><smiles>Cc1ccc(-c2c(F)c(F)c(-c3ccc(C)s3)c(F)c2F)s1</smiles> 


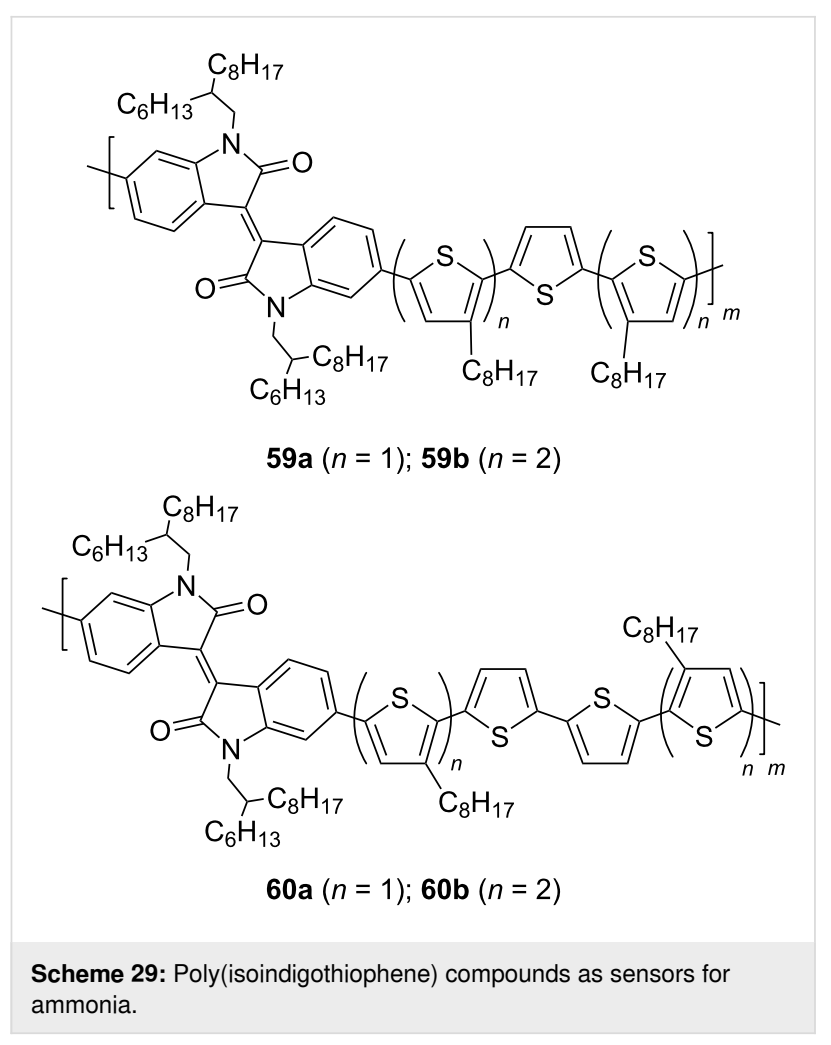

(chlorobenzene, $n$-butanol, DMF, isopropanol, and toluene) [107]. Therein, the best sensitivity was found towards $n$-butanol. The lower limit of detection was $100 \mathrm{ppm}$ with a response time of less than $10 \mathrm{~s}$.

The ability of polymeric isoindigo derivatives to strongly bind to carbon nanotubes due to $\pi$-stacking was used to create sensors for the determination of $\mathrm{NO}_{2}$ in the gaseous state (see polymer 61) and glucose in solution (see polymer 62) $[108,109]$. The limit of sensitivity of the sensor for nitrogen dioxide was $60 \mathrm{ppm}$ and for glucose $0.026 \mathrm{mM}$. For the example of the fairly simple arylamine series $\mathbf{6 3}$, the possibility of using isoindigo polymer for the detection of explosives (trinitrophenol and trinitrotoluene) in solution was demonstrated (Scheme 30) [110,111].

\section{Miscellaneous applications}

Taking into account the high thermal, atmospheric, mechanical, and redox stability of isoindigo polymers, various scientific groups focused their studies on the development of new directions for the practical application of these materials. Thus, Gu et al., using the example of a donor-acceptor-donor (D-A-D) polymer 64 containing a 3,4-ethylenedioxythiophene fragment, demonstrated the possibility of creating flexible IR displays based on isoindigo [112]. This polymer showed very good electrochromic characteristics, such as staining efficiency $\left(362 \mathrm{~cm}^{2} \cdot \mathrm{C}^{-1}\right.$ at $\left.1050 \mathrm{~nm}\right)$, fast switching time $(0.5 \mathrm{~s})$, high

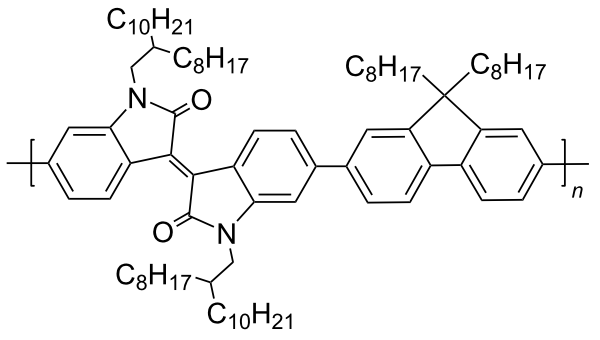

61

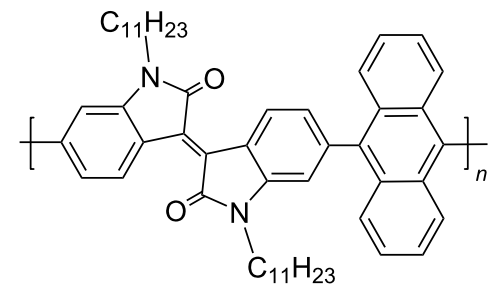

62

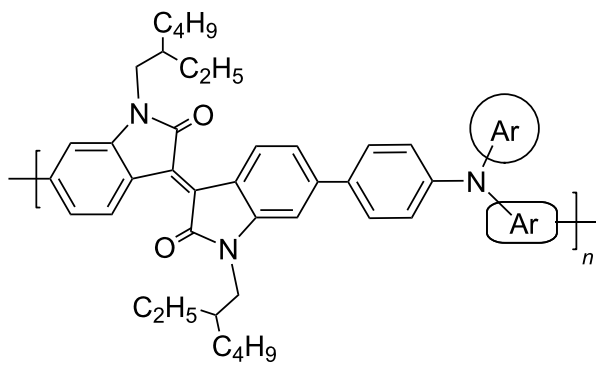

63

Scheme 30: Sensor devices based on poly(isoindigoaryl) compounds

optical contrast $(59 \%$ at $1500 \mathrm{~nm})$, and redox stability $(<8 \%$ after 4000 cycles).

Poly(isoindigothiophene) $\mathbf{6 5}$ containing sulfonate groups in the side chain was used as an anionic photoactive polyelectrolyte in a composite with platinum nanoparticles stabilized with poly(acrylic acid) [113]. Such a catalytic system, obtained by layer-by-layer self-assembly with the addition of poly(diallyldimethylammonium chloride) on the indium tin oxide surface, provided hydrogen formation in photoelectrolytic cycles with a Faraday yield of about $45 \%$.

The search for new stable polyfunctional materials for the mass spectrometric determination of low-molecular-weight compounds led the authors of reference [114] to the discovery of new properties of polyisoindigo 66. It was found that this polymer can be used as a two-mode matrix (in positive and negative modes), which is a rarity for the MALDI method. The detection limits were below 164 pmol for reserpine and below 245 pmol for cholic acid. 
More recently, another new application of polyisoindigos was discovered as a new conductive binder inside electrodes containing silicon nanoparticles coated with a carbon shell ( $\mathrm{Si} @ \mathrm{C})$ for lithium ion batteries [115]. The specific capacity of a battery designed using polyisoindigo 67 (up to $1400 \mathrm{~mA} \cdot \mathrm{h} / \mathrm{g}$ ) with high stability (up to 500 cycles) indicates a high potential of such structures in the search for alternatives to the existing polymer conductive binder mixed with carbon additives (Scheme 31).

Isoindigo derivatives have begun to find use in biomedical applications. Thus, nanoparticles of isoindigoid polymers have shown good potential as agents for photoacoustic and photothermal cancer therapy [116-121]. In this field, a number of condensed derivatives of oligoisoindigo 68-70, triphenylamine-containing monoisoindigo $\mathbf{7 1}$, and selenophenevinylene polymer 72 were investigated (Scheme 32 ). In terms of photothermal conversion (62-71\% yield), ribbon-like compounds turned out to be the most effective [120]. At the same time, in vivo experiments have shown the high efficiency of low-molecular-weight isoindigo $\mathbf{7 1}$ in oxygen sensitization for cancer therapy [121]. Therein, a high value (84\%) of the singlet oxygen quantum yield was obtained.

\section{Conclusion}

To summarize, it can be concluded that isoindigo is a promising platform for creating materials for various purposes - from organic solar cells and transistors to materials for biomedical applications. The possibility of easy modification and easy accessibility of the starting reagents for the synthesis of polysubstituted isoindigo derivatives provides the possibility of finetuning the properties and wide design of this bisheterocycle. In particular, to improve the characteristics of organic solar cells and OFET devices based on polymer derivatives of isoindigo, some of the most important factors are the planarity of the monomer unit, the electron donor/acceptor nature, the heterocyclic substituents, and the branching of the alkyl radical at the endocyclic nitrogen atom. Research on methods to obtain polymer isoindigo thin films and the use of additives will, in our opinion, significantly improve the efficiency of materials. In addition, the first work on combining polyaromatic acceptor and heterocyclic donor fragments in one macromolecule on the isoindigo platform showed the possibility of designing onecomponent nonfullerene solar cells. The high stability of polymeric isoindigo in air, at elevated temperature, under redox conditions, under laser irradiation, and the biocompatibility<smiles>[R]N1C(=O)/C(=C2/C(=O)N([R])c3cc(-c4sc(CC)c5c4OCCO5)ccc32)c2ccc(-c3sc(C)c4c3OCCO4)cc21</smiles>

$\mathrm{R}=\mathrm{C}_{6} \mathrm{H}_{13}, \mathrm{C}_{12} \mathrm{H}_{23}$<smiles>CCc1ccc(-c2ccc3c(c2)N(CCCS(N)(=O)=O)C(=O)C3=C2C(=O)N(CCCS(N)(=O)=O)c3cc(C)ccc32)s1</smiles>

65

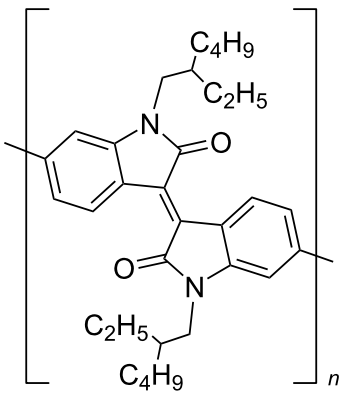

67 


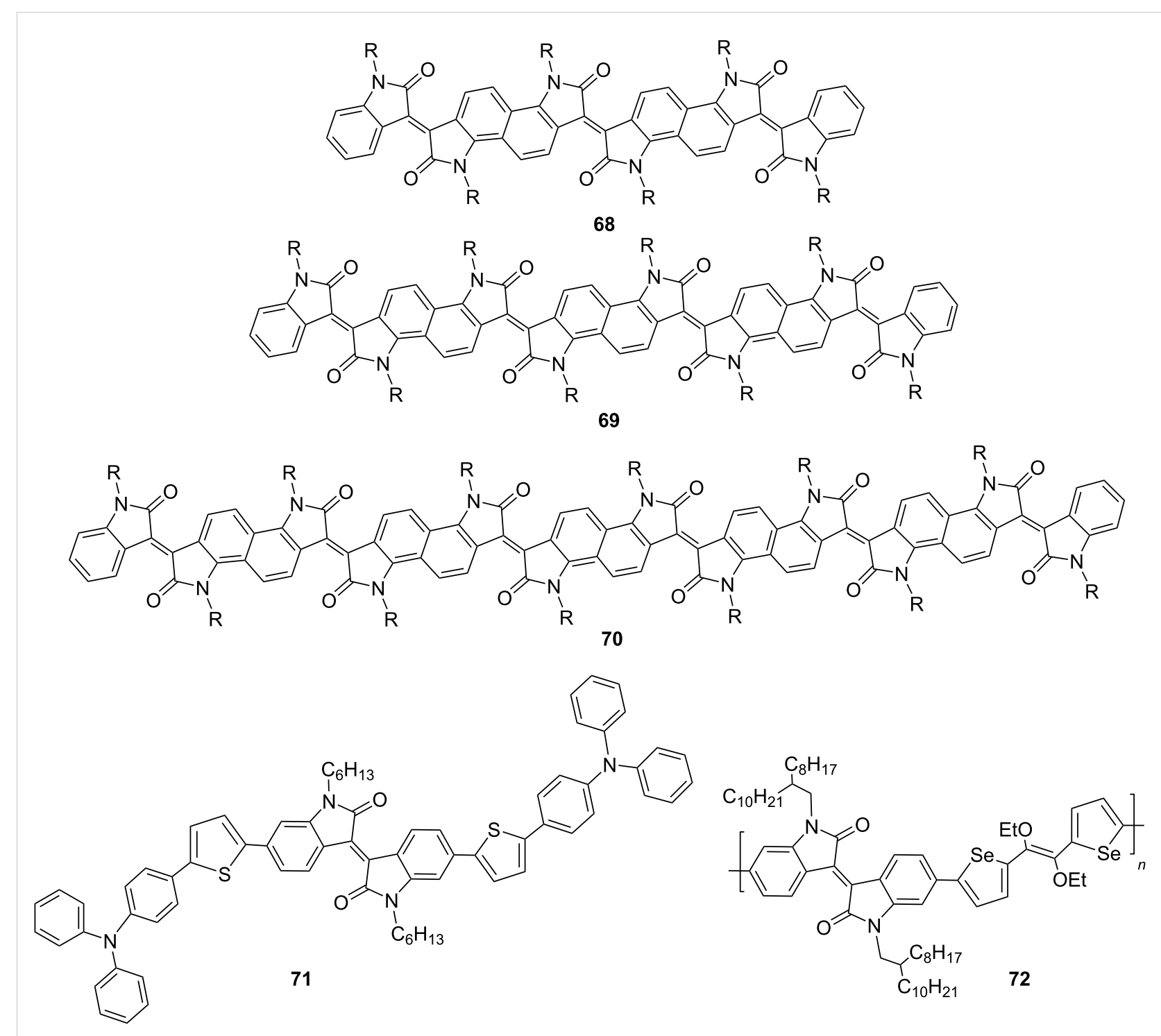

Scheme 32: Mono-, rod-like, and polymeric isoindigos as agents for photoacoustic and photothermal cancer therapy.

make it possible to conclude that the design of these compounds is promising for mass spectrometry, for catalysts for hydrogen production, and for photothermal cancer therapy.

\section{ORCID ${ }^{\circledR}$ iDs}

Andrei V. Bogdanov - https://orcid.org/0000-0002-2483-4742

\section{References}

1. Xiao, Z.; Hao, Y.; Liu, B.; Qian, L. Leuk. Lymphoma 2002, 43, 1763-1768. doi:10.1080/1042819021000006295

2. Huang, M.; Lin, H.-S.; Lee, Y. S.; Ho, P. C. Int. J. Oncol. 2014, 45, 1724-1734. doi:10.3892/ijo.2014.2548

3. Bogdanov, A. V.; Musin, L. I.; Mironov, V. F. ARKIVOC 2015, No. vi, 362-392. doi:10.3998/ark.5550190.p009.090

4. Stalder, R.; Mei, J.; Reynolds, J. R. Macromolecules 2010, 43, 8348-8352. doi:10.1021/ma1018445
5. Mei, J.; Graham, K. R.; Stalder, R.; Reynolds, J. R. Org. Lett. 2010, 12, 660-663. doi:10.1021/ol902512x

6. Deng, P.; Zhang, Q. Polym. Chem. 2014, 5, 3298-3305. doi:10.1039/c3py01598j

7. Tan, S. E.; Sarjadi, M. S. Polym. Sci., Ser. B 2017, 59, 479-496. doi:10.1134/s1560090417050141

8. Kini, G. P.; Jeon, S. J.; Moon, D. K. Adv. Mater. (Weinheim, Ger.) 2020, 32, 1906175. doi:10.1002/adma.201906175

9. Wang, Y.; Yu, Y.; Liao, H.; Zhou, Y.; McCulloch, I.; Yue, W. Acc. Chem. Res. 2020, 53, 2855-2868. doi:10.1021/acs.accounts.0c00480

10. Wang, L.; Bai, S.; Wu, Y.; Liu, Y.; Yao, J.; Fu, H. Angew. Chem., Int. Ed. 2020, 59, 2003-2007. doi:10.1002/anie.201912202

11. Eichhorn, S. H.; El-Ballouli, A. O.; Cassar, A.; Kaafarani, B. R. ChemPlusChem 2021, 86, 319-339. doi:10.1002/cplu.202100024 
12. Hadsadee, S.; Promarak, V.; Sudyoadsuk, T.; Keawin, T.; Kungwan, N.; Jungsuttiwong, S. J. Electron. Mater. 2020, 49, 318-332. doi:10.1007/s11664-019-07777-4

13. Liu, X.; Ye, L.; Zhao, W.; Zhang, S.; Li, S.; Su, G. M.; Wang, C.; Ade, H.; Hou, J. Mater. Chem. Front. 2017, 1, 2057-2064. doi:10.1039/c7qm00182g

14. Ganguly, A.; Zhu, J.; Kelly, T. L. J. Phys. Chem. C 2017, 121, 9110-9119. doi:10.1021/acs.jpcc.7b00742

15. Hu, J.; Xu, K.; Shen, L.; Wu, Q.; He, G.; Wang, J.-Y.; Pei, J.; Xia, J.; Sfeir, M. Y. Nat. Commun. 2018, 9, 2999. doi:10.1038/s41467-018-05389-w

16. Wen, Z.; Wu, J. I.-C. Chem. Commun. 2020, 56, 2008-2011. doi:10.1039/c9cc09670a

17. Jung, J. W. Dyes Pigm. 2017, 137, 512-517. doi:10.1016/j.dyepig.2016.10.042

18. Shaker, M.; Lee, J.-H.; Park, B.; Lee, S.; Lee, K.; Lee, J.-S. Synth. Met. 2020, 261, 116307. doi:10.1016/j.synthmet.2020.116307

19. Yu, D.; Liu, Y.; Fan, Q.; Xiao, M.; Tan, H.; Wang, Y.; Yang, R.; Zhu, W. Tetrahedron 2016, 72, 4543-4549. doi:10.1016/j.tet.2016.06.016

20. Dinçalp, H.; Saltan, G. M.; Zafer, C.; Mutlu, A. Spectrochim. Acta, Part A 2018, 202, 196-206. doi:10.1016/j.saa.2018.05.048

21. Zhou, H.; Sun, X.; Zhang, Z.; Yu, Y.; Huang, M.; Zhao, B. Dyes Pigm. 2018, 156, 403-409. doi:10.1016/j.dyepig.2018.04.030

22. Miao, J.; Meng, B.; Liu, J.; Wang, L. Chem. Commun. 2018, 54, 303-306. doi:10.1039/c7cc08497h

23. Cho, H.-H.; Han, G.; Younts, R.; Lee, W.; Gautam, B. R.; Lee, S.; Lee, C.; Kim, T.; Kim, F. S.; Gundogdu, K.; Kim, B. J. J. Mater. Chem. A 2017, 5, 21291-21299. doi:10.1039/c7ta06939a

24. Liang, L.; Chen, X.-Q.; Xiang, X.; Ling, J.; Shao, W.; Lu, Z.; Li, J.; Wang, W.; Li, W.-S. Org. Electron. 2017, 42, 93-101. doi:10.1016/j.orgel.2016.12.028

25. Shaker, M.; El-Hendawy, M. M.; Park, B.; Lee, K. New J. Chem. 2019, 43, 18126-18133. doi:10.1039/c9nj04101j

26. Li, M.; Zhang, G.; Xiong, L.; Zhu, M.; Pei, Y.; Peng, Q.; Liu, Y. Dyes Pigm. 2018, 158, 402-411. doi:10.1016/j.dyepig.2018.05.067

27. Ji, C.; Yin, L.; Xie, B.; Wang, X.; Li, X.; Zhang, J.-J.; Ni, J.; Li, Y. Synth. Met. 2016, 220, 448-454. doi:10.1016/j.synthmet.2016.07.014

28. Lee, J.-Y.; Lee, S.-M.; Lee, S.-H.; Kim, D.-H.; Lee, S. H.; Lee, Y.-S. Chem. Phys. Lett. 2016, 658, 103-108. doi:10.1016/j.cplett.2016.06.024

29. Chen, X.; Zhang, Z.; Liu, J.; Wang, L. Polym. Chem. 2017, 8, 5496-5503. doi:10.1039/c7py01089c

30. Miao, J.; Xu, H.; Meng, B.; Liu, J.; Wang, L. Chin. J. Chem. 2018, 36, 411-416. doi:10.1002/cjoc.201800006

31. Deng, P.; Lei, Y.; Wu, B.; Zheng, X.; Lu, Y.; Zhu, F.; Ong, B. S. Dyes Pigm. 2016, 134, 251-257. doi:10.1016/j.dyepig.2016.07.022

32. Kim, J.; Park, S. Y.; Han, G.; Chae, S.; Song, S.; Shim, J. Y.; Bae, E.; Kim, I.; Kim, H. J.; Kim, J. Y.; Suh, H. Polymer 2016, 95, 36-44. doi:10.1016/j.polymer.2016.04.061

33. Mori, H.; Hara, S.; Nishinaga, S.; Nishihara, Y. Macromolecules 2017, 50, 4639-4648. doi:10.1021/acs.macromol.7b00778

34. Park, G. E.; Choi, S.; Shin, J.; Cho, M. J.; Choi, D. H. Org. Electron. 2016, 34, 157-163. doi:10.1016/j.orgel.2016.04.016

35. Jung, E. H.; Ahn, H.; Jo, W. H.; Jo, J. W.; Jung, J. W. Dyes Pigm. 2019, 161, 113-118. doi:10.1016/j.dyepig.2018.09.048

36. Zhou, D.; Doumon, N. Y.; Abdu-Aguye, M.; Bartesaghi, D.; Loi, M. A.; Koster, L. J. A.; Chiechi, R. C.; Hummelen, J. C. RSC Adv. 2017, 7, 27762-27769. doi:10.1039/c7ra03539j
37. Grand, C.; Zajaczkowski, W.; Deb, N.; Lo, C. K.; Hernandez, J. L.; Bucknall, D. G.; Müllen, K.; Pisula, W.; Reynolds, J. R. ACS Appl. Mater. Interfaces 2017, 9, 13357-13368. doi:10.1021/acsami.6b16502

38. Chang, C.-Y.; Huang, Y.-C.; Tsao, C.-S.; Chen, C.-A.; Su, C.-J.; Su, W.-F. Phys. Chem. Chem. Phys. 2017, 19, 23515-23523. doi:10.1039/c7cp04238h

39. Tegegne, N. A.; Abdissa, Z.; Mammo, W.; Uchiyama, T.; Okada-Shudo, Y.; Galeotti, F.; Porzio, W.; Andersson, M. R.; Schlettwein, D.; Vohra, V.; Schwoerer, H. J. Phys. Chem. C 2020, 124, 9644-9655. doi:10.1021/acs.jpcc.9b11072

40. Liao, S.-F.; Chen, C.-T.; Chao, C.-Y. ACS Macro Lett. 2017, 6, 969-974. doi:10.1021/acsmacrolett.7b00547

41. Tegegne, N. A.; Wendimu, H.; Abdissa, Z.; Mammo, W.; Andersson, M. R.; Hone, F. G.; Andoshee, D. M.; Olaoye, O.; Bosman, G. J. Mater. Sci.: Mater. Electron. 2020, 31, 21303-21315. doi:10.1007/s10854-020-04642-7

42. Bini, K.; Xu, X.; Andersson, M. R.; Wang, E. Macromol. Chem. Phys. 2018, 219, 1700538. doi:10.1002/macp.201700538

43. Liu, S.; Firdaus, Y.; Thomas, S.; Kan, Z.; Cruciani, F.; Lopatin, S.; Bredas, J.-L.; Beaujuge, P. M. Angew. Chem., Int. Ed. 2018, 57, 531-535. doi:10.1002/anie.201709509

44. Schroeder, B. C.; Chiu, Y.-C.; Gu, X.; Zhou, Y.; Xu, J.; Lopez, J.; Lu, C.; Toney, M. F.; Bao, Z. Adv. Electron. Mater. 2016, 2, 1600104. doi:10.1002/aelm.201600104

45. Gu, K. L.; Zhou, Y.; Gu, X.; Yan, H.; Diao, Y.; Kurosawa, T.; Ganapathysubramanian, B.; Toney, M. F.; Bao, Z. Org. Electron. 2017, 40, 79-87. doi:10.1016/j.orgel.2016.10.033

46. Neophytou, M.; Bryant, D.; Lopatin, S.; Chen, H.; Hallani, R. K.; Cater, L.; McCulloch, I.; Yue, W. Macromol. Rapid Commun. 2018, 39, 1700820. doi:10.1002/marc.201700820

47. Zhu, L.; Jiang, C.; Chen, G.; Zhou, Z.; Li, Q. Org. Electron. 2017, 49, 278-285. doi:10.1016/j.orgel.2017.06.035

48. Seri, M.; Gedefaw, D.; Prosa, M.; Tessarolo, M.; Bolognesi, M.; Muccini, M.; Andersson, M. R. J. Polym. Sci., Part A: Polym. Chem. 2017, 55, 234-242. doi:10.1002/pola.28361

49. Jeon, S. J.; Lee, T. H.; Han, Y. W.; Moon, D. K. Polymer 2018, 149, 85-95. doi:10.1016/j.polymer.2018.04.032

50. Sun, X.; Zhang, Z.; Hou, R.; Huang, M.; Zhao, B.; Tan, S. Dyes Pigm. 2017, 139, 403-411. doi:10.1016/j.dyepig.2016.12.036

51. Cong, Z.; Liu, H.; Wang, W.; Liu, J.; Zhao, B.; Guo, Z.; Gao, C.; An, Z. Dyes Pigm. 2017, 146, 529-536. doi:10.1016/j.dyepig.2017.07.024

52. Kwon, N. Y.; Kang, H.; Park, S. H.; Kim, H. J.; Kim, C. Y.; Park, S.; Cho, M. J.; Choi, D. H. Dyes Pigm. 2020, 179, 108391. doi:10.1016/j.dyepig.2020.108391

53. Wang, X.; Cheng, C.; Li, Y.; Wang, F. Polymers (Basel, Switz.) 2018, 10, 331. doi:10.3390/polym10030331

54. Yu, C.; Xu, Y.; Li, C.; Feng, G.; Yang, F.; Li, J.; Li, W. Chin. J. Chem. 2018, 36, 515-518. doi:10.1002/cjoc.201800009

55. Zhang, B.; An, N.; Wu, H.; Geng, Y.; Sun, Y.; Ma, Z.; Li, W.; Guo, Q.; Zhou, E. Sci. China: Chem. 2020, 63, 1262-1271. doi:10.1007/s11426-020-9777-1

56. Li, Z.; Xu, X.; Zhang, W.; Genene, Z.; Mammo, W.; Yartsev, A.; Andersson, M. R.; Janssen, R. A. J.; Wang, E. J. Mater. Chem. A 2017, 5, 11693-11700. doi:10.1039/c6ta09379e

57. Wang, X.; Lv, L.; Gu, W.; Wang, X.; Dong, T.; Yang, Z.; Cao, H.; Huang, H. Dyes Pigm. 2017, 140, 141-149. doi:10.1016/j.dyepig.2017.01.041 
58. Peng, W.; Tan, H.; Xiao, M.; Chen, J.; Tao, Q.; Duan, X.; Wang, Y.; Liu, Y.; Yang, R.; Zhu, W. Eur. Polym. J. 2016, 81, 307-315. doi:10.1016/j.eurpolymj.2016.06.013

59. Gao, X.; Zhao, Z. Sci. China: Chem. 2015, 58, 947-968. doi:10.1007/s11426-015-5399-5

60. Yuvaraja, S.; Nawaz, A.; Liu, Q.; Dubal, D.; Surya, S. G.; Salama, K. N.; Sonar, P. Chem. Soc. Rev. 2020, 49, 3423-3460. doi:10.1039/c9cs00811j

61. Yang, J.; Zhao, Z.; Wang, S.; Guo, Y.; Liu, Y. Chem 2018, 4, 2748-2785. doi:10.1016/j.chempr.2018.08.005

62. Shinamura, S.; Osaka, I.; Miyazaki, E.; Takimiya, K. Heterocycles 2011, 83, 1187-1204. doi:10.3987/rev-10-690

63. Larik, F. A.; Faisal, M.; Saeed, A.; Abbas, Q.; Kazi, M. A.; Abbas, N.; Thebo, A. A.; Khan, D. M.; Channar, P. A. J. Mater. Sci.: Mater. Electron. 2018, 29, 17975-18010. doi:10.1007/s10854-018-9936-9

64. Quinn, J. T. E.; Zhu, J.; Li, X.; Wang, J.; Li, Y. J. Mater. Chem. C 2017, 5, 8654-8681. doi:10.1039/c7tc01680h

65. Liu, Y.; Wang, F.; Chen, J.; Wang, X.; Lu, H.; Qiu, L.; Zhang, G. Macromolecules 2018, 51, 370-378. doi:10.1021/acs.macromol.7b02309

66. You, L.; Chaudhry, S. T.; Zhao, Y.; Liu, J.; Zhao, X.; He, J.; Mei, J. Polym. Chem. 2017, 8, 2438-2441. doi:10.1039/c7py00237h

67. Ashizawa, M.; Zheng, Y.; Tran, H.; Bao, Z. Prog. Polym. Sci. 2020, 100, 101181. doi:10.1016/j.progpolymsci.2019.101181

68. Zhu, X.; Zhang, S.-R.; Zhou, Y.; Han, S.-T. Polym. Int. 2021, 70, 358-366. doi:10.1002/pi.6006

69. Ashizawa, M.; Masuda, N.; Higashino, T.; Kadoya, T.; Kawamoto, T.; Matsumoto, H.; Mori, T. Org. Electron. 2016, 35, 95-100. doi:10.1016/j.orgel.2016.05.013

70. Shaker, M.; Park, B.; Lee, S.; Lee, K. Dyes Pigm. 2020, 172, 107784. doi:10.1016/j.dyepig.2019.107784

71. Trinh, C. K.; Lee, H.-J.; Choi, J. W.; Shaker, M.; Kim, W.; Lee, J.-S. New J. Chem. 2018, 42, 2557-2563. doi:10.1039/c7nj04440b

72. Shaker, M.; Hayashi, H.; Yamada, H. Dyes Pigm. 2021, 184, 108806. doi:10.1016/j.dyepig.2020.108806

73. Qiao, X.; Wei, Q.; Wu, H.; Li, H. Macromol. Chem. Phys. 2020, 221 , 2000189. doi:10.1002/macp.202000189

74. Lin, Y.-C.; Chen, F.-H.; Chiang, Y.-C.; Chueh, C.-C.; Chen, W.-C. ACS Appl. Mater. Interfaces 2019, 11, 34158-34170. doi:10.1021/acsami.9b10943

75. Xue, G.; Zhao, X.; Qu, G.; Xu, T.; Gumyusenge, A.; Zhang, Z.; Zhao, Y.; Diao, Y.; Li, H.; Mei, J. ACS Appl. Mater. Interfaces 2017, 9, 25426-25433. doi:10.1021/acsami.7b07624

76. Tran, D. T.; Gumyusenge, A.; Luo, X.; Roders, M.; Yi, Z.; Ayzner, A. L.; Mei, J. ACS Appl. Polym. Mater. 2020, 2, 91-97. doi:10.1021/acsapm.9b00999

77. Shih, C.-C.; Lee, W.-Y.; Lu, C.; Wu, H.-C.; Chen, W.-C. Adv. Electron. Mater. 2017, 3, 1600477. doi:10.1002/aelm.201600477

78. Li, Q.-Y.; Yao, Z.-F.; Lu, Y.; Zhang, S.; Ahmad, Z.; Wang, J.-Y.; Gu, X.; Pei, J. Adv. Electron. Mater. 2020, 6, 2000080. doi:10.1002/aelm.202000080

79. Yang, J.; Zhao, Z.; Geng, H.; Cheng, C.; Chen, J.; Sun, Y.; Shi, L.; Yi, Y.; Shuai, Z.; Guo, Y.; Wang, S.; Liu, Y. Adv. Mater. (Weinheim, Ger.) 2017, 29, 1702115. doi:10.1002/adma.201702115

80. Liu, L.; Du, Y.; Ge, F.; Wang, X.; Zhang, G.; Lu, H.; Qiu, L. Appl. Phys. Lett. 2018, 113, 102102. doi:10.1063/1.5042629

81. Dharmapurikar, S. S.; Arulkashmir, A.; Mahale, R. Y.; Chini, M. K. J. Appl. Polym. Sci. 2017, 134, 45461. doi:10.1002/app.45461
82. Lee, J.; Shin, E.-S.; Kim, Y.-J.; Noh, Y.-Y.; Yang, C. J. Mater. Chem. C 2020, 8, 296-302. doi:10.1039/c9tc05641f

83. Wen, H.-F.; Wu, H.-C.; Aimi, J.; Hung, C.-C.; Chiang, Y.-C.; Kuo, C.-C.; Chen, W.-C. Macromolecules 2017, 50, 4982-4992. doi:10.1021/acs.macromol.7b00860

84. Zhang, G.; Dai, Y.; Liu, Y.; Liu, J.; Lu, H.; Qiu, L.; Cho, K. Polym. Chem. 2017, 8, 3448-3456. doi:10.1039/c7py00484b

85. Yen, H.-C.; Lin, Y.-C.; Chen, W.-C. Macromolecules 2021, 54, 1665-1676. doi:10.1021/acs.macromol.0c02322

86. Ding, Y.; Jiang, L.; Du, Y.; Kim, S.; Wang, X.; Lu, H.; Zhang, G.; Cho, K.; Qiu, L. Chem. Commun. 2020, 56, 11867-11870. doi:10.1039/d0cc01497d

87. Shin, E.-S.; Ha, Y. H.; Gann, E.; Lee, Y.-J.; Kwon, S.-K.; McNeill, C. R.; Noh, Y.-Y.; Kim, Y.-H. ACS Appl. Mater. Interfaces 2018, 10, 13774-13782. doi:10.1021/acsami.8b03131

88. Gao, Y.; Deng, Y.; Tian, H.; Zhang, J.; Yan, D.; Geng, Y.; Wang, F. Adv. Mater. (Weinheim, Ger.) 2017, 29, 1606217. doi:10.1002/adma.201606217

89. Shi, K.; Zhang, W.; Liu, X.; Zou, Y.; Yu, G. Polymer 2017, 112, 180-188. doi:10.1016/j.polymer.2017.02.009

90. Wei, C.; Tang, Z.; Zhang, W.; Huang, J.; Zhou, Y.; Wang, L.; Yu, G. Polym. Chem. 2020, 11, 7340-7348. doi:10.1039/d0py01399d

91. Park, W.-T.; Kim, G.; Yang, C.; Liu, C.; Noh, Y.-Y. Adv. Funct. Mater. 2016, 26, 4695-4703. doi:10.1002/adfm.201504908

92. Liu, Q.; Bottle, S. E.; Sonar, P. Adv. Mater. (Weinheim, Ger.) 2020, 32, 1903882. doi:10.1002/adma.201903882

93. Du, Y.; Ding, Y.; Ge, F.; Wang, X.; Ma, S.; Lu, H.; Zhang, G.; Qu, L. Dyes Pigm. 2019, 164, 27-34. doi:10.1016/j.dyepig.2019.01.003

94. Bao, W. W.; Li, R.; Dai, Z. C.; Tang, J.; Shi, X.; Geng, J. T.; Deng, Z. F.; Hua, J. Front. Chem. (Lausanne, Switz.) 2020, 8, 679. doi:10.3389/fchem.2020.00679

95. Shaker, M.; Park, B.; Lee, J.-H.; Kim, W.; Trinh, C. K.; Lee, H.-J.; Choi, J. w.; Kim, H.; Lee, K.; Lee, J.-S. RSC Adv. 2017, 7, 16302-16310. doi:10.1039/c7ra01726j

96. Dharmapurikar, S. S.; Chithiravel, S.; Mane, M. V.; Deshmukh, G.; Krishnamoorthy, K. Chem. Phys. Lett. 2018, 695, 51-58. doi:10.1016/..cplett.2018.01.052

97. Onwubiko, A.; Yue, W.; Jellett, C.; Xiao, M.; Chen, H.-Y.; Ravva, M. K.; Hanifi, D. A.; Knall, A.-C.; Purushothaman, B.; Nikolka, M.; Flores, J.-C.; Salleo, A.; Bredas, J.-L.; Sirringhaus, H.; Hayoz, P.; McCulloch, I. Nat. Commun. 2018, 9, 416. doi:10.1038/s41467-018-02852-6

98. Zhang, H.; Zhao, Z.; Zhao, N.; Xie, Y.; Cai, M.; Wang, X.; Liu, Y.; Lan, Z.; Wan, X. RSC Adv. 2017, 7, 25009-25018. doi:10.1039/c7ra01139c

99. Zhao, N.; Ai, N.; Cai, M.; Wang, X.; Pei, J.; Wan, X. Polym. Chem. 2016, 7, 235-243. doi:10.1039/c5py01488c

100.Ganguly, A.; He, K.; Hendsbee, A. D.; Abdelsamie, M.; Bennett, R. N.; Li, Y.; Toney, M. F.; Kelly, T. L. ACS Appl. Mater. Interfaces 2020, 12, 14265-14271. doi:10.1021/acsami.9b23064

101.Bennett, R. N.; Hendsbee, A. D.; Ngai, J. H. L.; Ganguly, A.; Li, Y.; Kelly, T. L. ACS Appl. Electron. Mater. 2020, 2, 2039-2048. doi:10.1021/acsaelm.0c00305

102. Song, H.; Deng, Y.; Jiang, Y.; Tian, H.; Geng, Y. Chem. Commun. 2018, 54, 782-785. doi:10.1039/c7cc08603b

103. Huang, Y.; Chen, H.; Yang, J.; Tian, W.; Wang, W. Polym. Chem. 2017, 8, 4878-4886. doi:10.1039/c7py00810d

104.Jo, J. W.; Kim, J. H.; Jung, J. W. Dyes Pigm. 2016, 133, 333-338. doi:10.1016/j.dyepig.2016.06.014 
105.Wu, H.-C.; Hong, C.-W.; Chen, W.-C. Polym. Chem. 2016, 7, 4378-4392. doi:10.1039/c6py00726k

106.Lu, C.-F.; Shih, C.-W.; Chen, C.-A.; Chin, A.; Su, W.-F. Adv. Funct. Mater. 2018, 28, 1803145. doi:10.1002/adfm.201803145

107.Vu, D. L.; Lin, T.-F.; Lin, T.-H.; Wu, M.-C. Polymers (Basel, Switz.) 2020, 12, 455. doi:10.3390/polym12020455

108.Zhou, C.; Zhao, J.; Ye, J.; Tange, M.; Zhang, X.; Xu, W.; Zhang, K.; Okazaki, T.; Cui, Z. Carbon 2016, 108, 372-380. doi:10.1016/j.carbon.2016.07.035

109.Soylemez, S.; Goker, S.; Toppare, L. New J. Chem. 2019, 43, 13979-13984. doi:10.1039/c9nj02546d

110.Lu, Q.; Zhang, X.; Cai, W.; Wang, Y.; Yang, C.; Chen, Y.; Zhang, W.; Zhang, Z.; Niu, H.; Wang, W. Sol. Energy Mater. Sol. Cells 2019, 200, 109979. doi:10.1016/j.solmat.2019.109979

111.Lu, Q.; Cai, W.; Zhang, X.; Yang, C.; Ge, H.; Chen, Y.; Niu, H.; Wang, W. Eur. Polym. J. 2018, 108, 124-137. doi:10.1016/j.eurpolymj.2018.08.042

112.Gu, H.; Ming, S.; Lin, K.; Chen, S.; Liu, X.; Lu, B.; Xu, J. Electrochim. Acta 2018, 260, 772-782. doi:10.1016/j.electacta.2017.12.033

113.Leem, G.; Black, H. T.; Shan, B.; Bantang, J. P. O.; Meyer, T. J.; Reynolds, J. R.; Schanze, K. S. ACS Appl. Energy Mater. 2018, 1 , 62-67. doi:10.1021/acsaem.7b00223

114. Horatz, K.; Giampà, M.; Karpov, Y.; Sahre, K.; Bednarz, H.; Kiriy, A.; Voit, B.; Niehaus, K.; Hadjichristidis, N.; Michels, D. L.; Lissel, F. J. Am. Chem. Soc. 2018, 140, 11416-11423. doi:10.1021/jacs.8b06637

115. Mery, A.; Bernard, P.; Valero, A.; Alper, J. P.; Herlin-Boime, N.; Haon, C.; Duclairoir, F.; Sadki, S. J. Power Sources 2019, 420, 9-14. doi:10.1016/j.jpowsour.2019.02.062

116.Jiang, Y.; Zheng, X.; Deng, Y.; Tian, H.; Ding, J.; Xie, Z.; Geng, Y.; Wang, F. Angew. Chem., Int. Ed. 2018, 57, 10283-10287. doi:10.1002/anie.201800512

117.Yang, T.; Liu, L.; Deng, Y.; Guo, Z.; Zhang, G.; Ge, Z.; Ke, H.; Chen, H. Adv. Mater. (Weinheim, Ger.) 2017, 29, 1700487. doi:10.1002/adma.201700487

118.Dong, T.; Wen, K.; Chen, J.; Xie, J.; Fan, W.; Ma, H.; Yang, L.; Wu, X.; Xu, F.; Peng, A.; Huang, H. Adv. Funct. Mater. 2018, 28 , 1800135. doi:10.1002/adfm.201800135

119.Chang, K.; Liu, Y.; Hu, D.; Qi, Q.; Gao, D.; Wang, Y.; Li, D.; Zhang, X.; Zheng, H.; Sheng, Z.; Yuan, Z. ACS Appl. Mater. Interfaces 2018, 10 , 7012-7021. doi:10.1021/acsami.8b00759

120.Jiang, Y.; Duan, X.; Bai, J.; Tian, H.; Ding, D.; Geng, Y. Biomaterials 2020, 255, 120179. doi:10.1016/j.biomaterials.2020.120179

121.Shao, W.; Yang, C.; Li, F.; Wu, J.; Wang, N.; Ding, Q.; Gao, J.; Ling, D. Nano-Micro Lett. 2020, 12, 147. doi:10.1007/s40820-020-00474-6

\section{License and Terms}

This is an Open Access article under the terms of the Creative Commons Attribution License (https://creativecommons.org/licenses/by/4.0). Please note that the reuse, redistribution and reproduction in particular requires that the author(s) and source are credited and that individual graphics may be subject to special legal provisions.

The license is subject to the Beilstein Journal of Organic Chemistry terms and conditions: (https://www.beilstein-journals.org/bjoc/terms)

The definitive version of this article is the electronic one which can be found at: https://doi.org/10.3762/bjoc.17.111 